\title{
Intact polar and core glycerol dibiphytanyl glycerol tetraether lipids in the Arabian Sea oxygen minimum zone. Part II: Selective preservation and degradation in sediments and consequences for the $\mathrm{TEX}_{86}$
}

\author{
Sabine K. Lengger ${ }^{\mathrm{a}}$, Ellen C. Hopmans ${ }^{\mathrm{a}}$, Gert-Jan Reichart ${ }^{\mathrm{b}}$, Klaas G.J. Nierop ${ }^{\mathrm{b}}$, \\ Jaap S. Sinninghe Damsté ${ }^{\mathrm{a}, \mathrm{b}}$, Stefan Schouten ${ }^{\mathrm{a}, \mathrm{b}, *}$

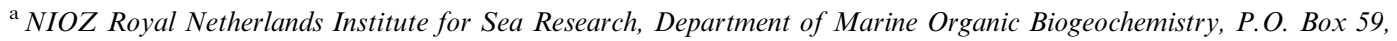 \\ 1790 AB Den Burg (Texel), The Netherlands \\ ${ }^{\mathrm{b}}$ Faculty of Geosciences, Department of Earth Sciences-Organic Geochemistry, Utrecht University, P.O. Box 80021, 3508 TA Utrecht, \\ The Netherlands
}

Received 7 July 2011; accepted in revised form 1 May 2012; available online 10 May 2012

\begin{abstract}
The $\mathrm{TEX}_{86}$ is a proxy based on a ratio of pelagic archaeal glycerol dibiphytanyl glycerol tetraether lipids (GDGTs), and used for estimating past sea water temperatures. Concerns exist that in situ production of GDGTs lipids by sedimentary Archaea may affect its validity. In this study, we investigated the influence of benthic GDGT production on the TEX 86 by analyzing the concentrations and distributions of GDGTs present as intact polar lipids (IPLs) and as core lipids (CLs) in three sediment cores deposited under contrasting redox conditions across a depth range from 900 to $3000 \mathrm{~m}$ below sea level in and below the Arabian Sea oxygen minimum zone (OMZ). Direct analysis of IPLs with crenarchaeol as CL via HPLC/ESI-MS ${ }^{2}$ revealed that surface sediments in the OMZ were relatively depleted in the phospholipid hexose, phosphohexose (HPH)-crenarchaeol compared to suspended particulate matter from the water column, suggesting preferential and rapid degradation of this IPL. In sediment cores recovered from deeper, more oxic environments, concentrations of HPH-crenarchaeol peaked at the surface, probably due to in situ production by ammonia-oxidizing Archaea, followed by a rapid decrease with increasing depth. No surface maximum was observed in the sediment core from within the OMZ. In contrast, the glycolipids, monohexose-crenarchaeol and dihexose-crenarchaeol, did not change in concentration with depth in the sediment, indicating that they were relatively well preserved and likely mostly derived from fossil pelagic GDGTs. These results suggest that phospholipids are more sensitive to degradation, while glycolipids might be preserved over longer time scales, in line with previous incubation and modeling studies. Furthermore, in situ produced IPL-GDGTs did not accumulate as IPLs, and did not influence the CL-TEX 86 . This suggests that in-situ produced GDGT lipids were more susceptible to degradation than fossil CL and IPL and did not accumulate as CL. In agreement, no significant changes of $\mathrm{TEX}_{86}$ with sediment depth in the core lipids were observed. However, consistent differences between IPL-derived TEX 86 and CL-TEX 86 were found. These could be explained by a different composition of CL-GDGT of the glyco- and phospholipids, in combination with dissimilar degradation rates of phospholipids vs. glycolipids. We also observed consistent differences in both IPL-derived and CL-TEX ${ }_{86}$ between the different cores, equivalent to $3{ }^{\circ} \mathrm{C}$ when converted to temperature, despite the proximity of the core locations. These differences may potentially be due to a larger addition of GDGTs produced in deeper, colder waters to the (sub)surface-derived GDGTs for the deeper core sites. (c) 2012 Elsevier Ltd. All rights reserved.
\end{abstract}

\footnotetext{
* Corresponding author at: NIOZ Royal Netherlands Institute for Sea Research, Department of Marine Organic Biogeochemistry, P.O. Box 59, 1790 AB Den Burg (Texel), The Netherlands.

E-mail address: stefan.schouten@nioz.nl (S. Schouten).
} 


\section{INTRODUCTION}

The domain of Archaea consists of four kingdoms, the Eury-, Cren- and Nanoarchaeota as well as the recently, on the basis of genome analysis of enriched Archaea, proposed Thaumarchaeota (Brochier-Armanet et al., 2008; Spang et al., 2010), formerly classified as Group I Crenarchaeota. All Thaumarchaeota known so far are capable of ammonia oxidation (Könneke et al., 2005; de la Torre et al., 2008; Hatzenpichler et al., 2008; Park et al., 2010) and are widespread in non-extreme environments (DeLong, 1992; Fuhrman et al., 1992; DeLong et al., 1998; Schouten et al., 2000). They occur in the ocean (Karner et al., 2001), in soils (Leininger et al., 2006) and lakes (Schleper et al., 1997), and in marine and estuarine surface sediments (Francis et al., 2005; Beman and Francis, 2006; Park et al., 2008). In the present day ocean, these Archaea are found to be among the most abundant micro-organisms (Karner et al., 2001; Agogué et al., 2008).

The membrane lipids of the domain Archaea are distinctive as they consist of isopranyl chains linked to a glycerol backbone via ether bonds (Kates et al., 1965; Langworthy et al., 1972, 1974). Most of the cultivated Crenarchaeota and Thaumarchaeota produce tetraether lipids consisting of two back-to-back linked diethers (glycerol dibiphytanyl glycerol tetraethers, GDGTs) which can have varying numbers of cyclopentane moieties (Macalady et al., 2004; Koga and Morii, 2005; Schouten et al., 2008; Pitcher et al., 2010). Thaumarchaeota contain in addition a specific GDGT, crenarchaeol, which contains not only cyclopentane moieties but also one cyclohexane moiety (Sinninghe Damsté et al., 2002b). GDGTs are preserved well in the sedimentary record and can thus be used as biomarkers for this group of Archaea (e.g. Kuypers et al., 2001; Pancost et al., 2001; Ingalls et al., 2006; Coolen et al., 2007).

Schouten et al. (2002) found a correlation between sea surface temperature (SST) and the distribution of four specific GDGTs present in sediment core tops (GDGT-1, -2, -3 and $-4^{\prime}$, Fig. 1a) and they expressed this in the TEX ${ }_{86}$ index. This ratio has been calibrated with a global set of core tops (Kim et al., 2008, 2010) and has been frequently used in studies to reconstruct past changes in SST (e.g. Huguet et al., 2006c; Forster et al., 2007; Liu et al., 2009; Bijl et al., 2009). The proxy is based on the assumption that the distribution of pelagic thaumarchaeal membrane lipids changes with temperature, which has been suggested previously for other phyla of Archaea (Gliozzi et al., 1983; Gabriel and Chong, 2000; Cavicchioli, 2006), and that this signal is preserved in sediments. The temperature-dependence of the GDGT distribution was shown in mesocosms of enriched ammonia-oxidizing Archaea (AOA) (Wuchter et al., 2004; Schouten et al., 2007) as well as suspended particulate matter from marine waters $<100 \mathrm{~m}$ depth (Wuchter et al., 2005). It has been observed that, even though genetic markers for Thaumarchaeota are present throughout the water column (e.g. Karner et al., 2001; Herndl et al., 2005), surface sediment TEX $_{86}$ values correspond to upper water column temperatures (Kim et al., 2008, 2010). This was explained with the assumption that mainly GDGTs from the upper part of the water column are exported to the sediment by attachment to and sinking with marine snow via organisms which are mainly present in the upper $200 \mathrm{~m}$ of the water column (Wakeham et al., 2003; Wuchter et al., 2005; Huguet et al., 2006a).

Using 16S rRNA gene and biomarker analysis, Archaea have also been suggested to be present and active in sediments (Biddle et al., 2006; Lipp et al., 2008). Production of one or more of the GDGTs used for calculation of the TEX $_{86}$ by sedimentary Archaea can thus potentially lead to a significant bias in the past sea surface temperature estimations (Lipp et al., 2008; Lipp and Hinrichs, 2009). The presence of GDGTs of subsurface Archaea was evident from detection of intact polar GDGTs (IPL-GDGTs), i.e. GDGTs with polar headgroups such as glycosidic or phosphate headgroups, the form in which they actually occur in the archaeal cell membrane (Fig. 1b, de Rosa and Gambacorta, 1988; Koga and Nakano, 2008). IPL-GDGTs are used as a proxy for living Archaea as the headgroups are thought to be cleaved quickly after cell death through enzymatic hydrolysis yielding core lipids, CL-GDGTs (Zink et al., 2003; Biddle et al., 2006; Huguet et al., 2010). The term 'living' in this sense entails all viable, i.e. active as well as dormant, cells which possess an intact membrane (cf. Stevenson, 1978; Lebaron et al., 2001; Luna et al., 2002). IPL-GDGTs found in sediments and reported up to now as indicative of living Archaea are glycolipids with monohexose- and dihexose-GDGTs and GDGTs with a loss of m/z 341 (Biddle et al., 2006; Lipp and Hinrichs, 2009; Schubotz et al., 2009). However, IPL-studies of crenarchaeolproducing Thaumarchaeota in enrichments and cultures revealed the presence of glycolipids, but also of phosphatecontaining GDGTs, i.e. phosphohexose and hexose, phosphohexose-GDGTs (Schouten et al., 2008; Pitcher et al., 2010, 2011) which, up to now, have not been reported in sediments. Harvey et al. (1986) reported that, in a shortterm incubation study, glycosidic ether-lipids were more stable than diacylglycerolphosphoester-lipids and thus degradation rates of glycolipids may be much slower than the degradation rates of phosphate-containing lipids (Harvey et al., 1986). Hence, glycolipid-GDGTs could also be at least partially of fossil pelagic origin (Schouten et al., 2010). It is thus presently not clear whether IPLs present in surface sediments are all in situ produced and if and how archaeal benthic production affects $\mathrm{TEX}_{86}$ values of fossil core lipids.

To address this issue, we analyzed sediments from the Arabian Sea which possesses a well-developed oxygen minimum zone (OMZ) with almost no detectable concentrations of molecular oxygen in its core (Wyrtki, 1971, 1973; Olson et al., 1993). Mean $\mathrm{O}_{2}$ concentration in the core of OMZ has been reported to be as low as $13 \mu \mathrm{M}$, with seasonal minima ranging from 0.1 to $1.0 \mu \mathrm{M}$ (Paulmier and Ruiz-Pino, 2009). Jensen et al. (2011) found apparent anoxic conditions in the Central and NE-Arabian Sea OMZ between 100 and $800 \mathrm{~m}$ depth, deploying a recently described highly sensitive oxygen sensor with a detection limit of $90 \mathrm{nM}$ (Revsbech et al., 2009). The Murray Ridge is a sub-marine high in the Northern Arabian Sea which protrudes into the core of the OMZ (Fig. 2). The relief allows sampling of sediments from different water depths in close 
(a)

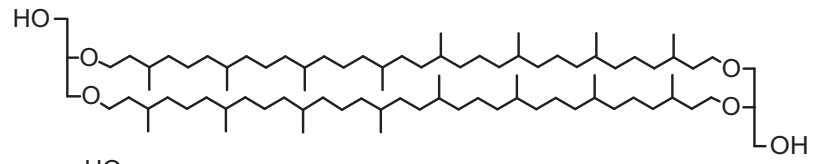

GDGT-0

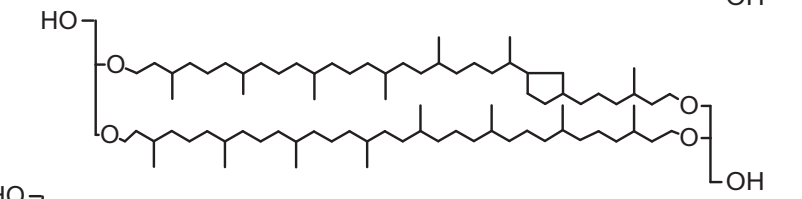

GDGT-1

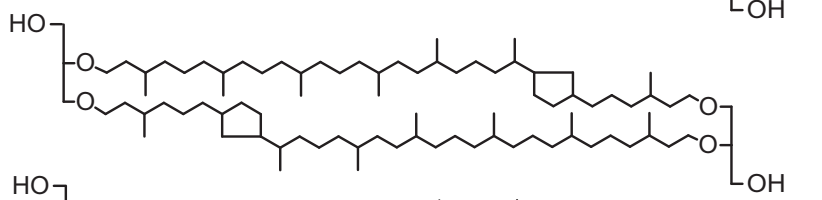

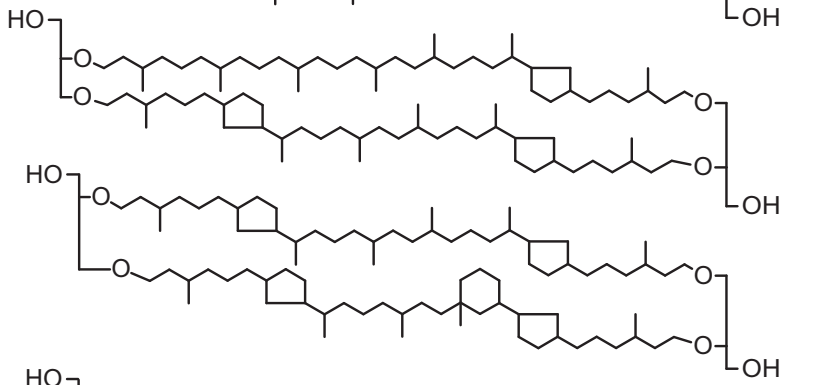

GDGT-3

Crenarchaeol

(b)

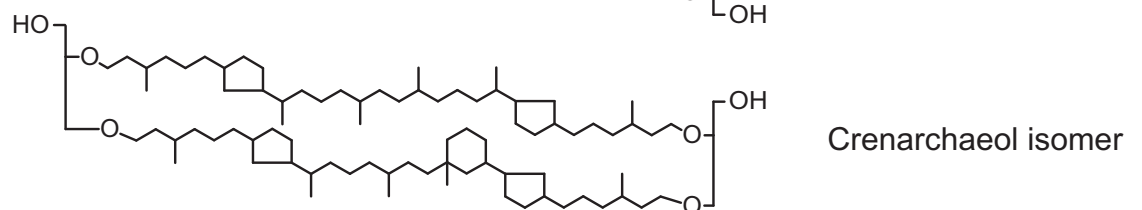

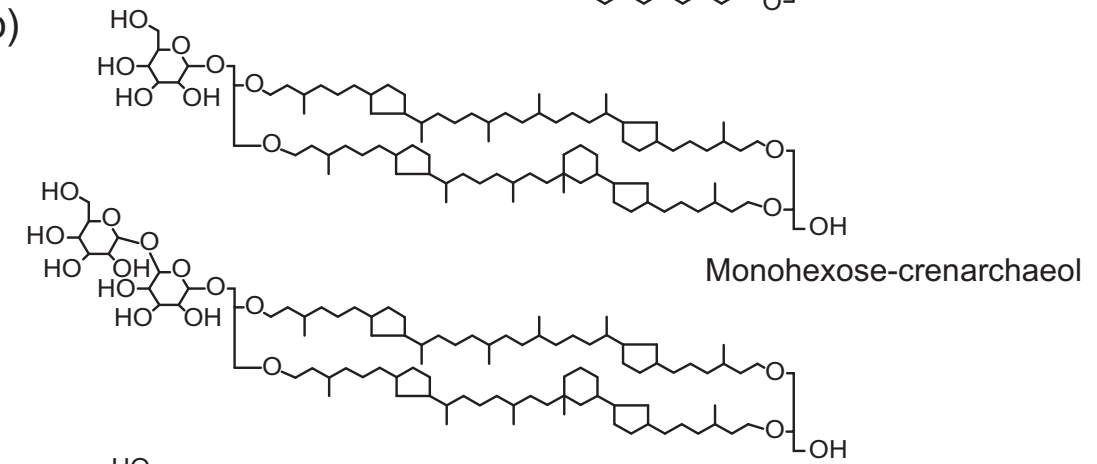

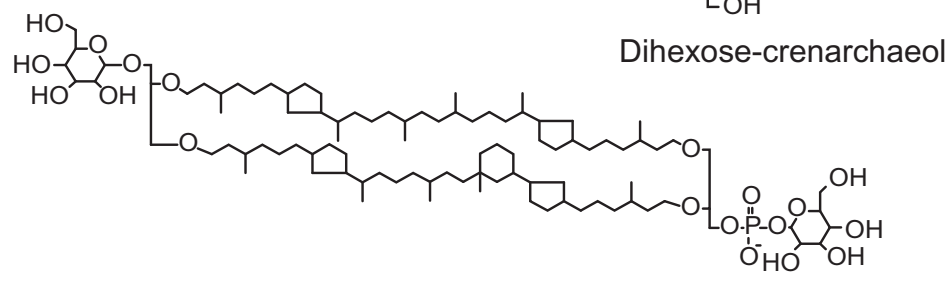

Hexose, phosphohexose-crenarchaeol

Fig. 1. Core lipid GDGTs (a) and crenarchaeol-containing IPLs (b) analyzed in the sediment cores.

lateral proximity, and hence containing similar pelagic material, but at contrasting bottom water oxygen concentrations. Here, we analyzed three sediment cores, from within the $\mathrm{OMZ}$, below the $\mathrm{OMZ}$ and from the oxygenated bottom waters. Similar to the companion paper on the water column (Schouten et al., 2012), we directly measured crenarchaeol with glyco- and phosphoglyco-headgroups and quantitatively compared CL- and IPL-derived GDGT concentrations and distributions as well as $\mathrm{TEX}_{86}$ values. The lipid profiles are discussed with respect to the impact of sedimentary in situ production and preservation potential of archaeal IPLs on the TEX 86 .

\section{MATERIALS AND METHODS}

\subsection{Sampling}

Sediment cores (multi cores) were taken in the Northern Arabian Sea along a transect on the Murray Ridge during the PASOM cruise (64PE301) in January 2009 (Fig. 2). The 

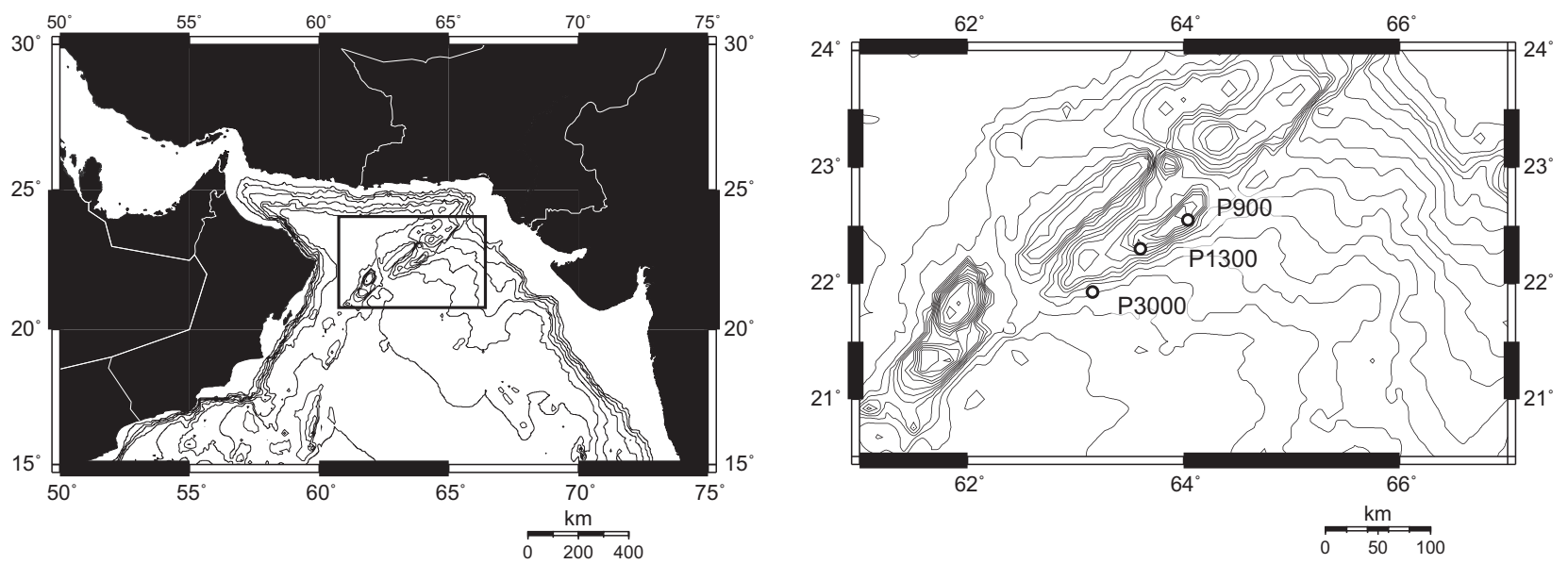

Fig. 2. Map of the Arabian Sea (left) and of the Murray Ridge (right). Stations sampled during the PASOM cruise are marked with a circle. Station P3000 is equivalent to the station investigated in the companion publication (Schouten et al., 2012).

sampling locations, the water depths and oxygen concentrations of the bottom water are summarized in Table 1 . Three sediment cores were taken at three depths, $900 \mathrm{~m}$ below sea surface (mbss) (station 1, further referred to as P900; within the OMZ), 1300 mbss (station 4 or P1300, just below the OMZ) and 3000 mbss (station 10 or P3000, well below the OMZ). The sediment cores of $20-36 \mathrm{~cm}$ length were sliced on board the $R / V$ Pelagia in $0.5-4 \mathrm{~cm}$ intervals and stored in geochemical bags. They were frozen immediately at $-80{ }^{\circ} \mathrm{C}$ and further transported and stored at $-20^{\circ} \mathrm{C}$. Prior to analysis, the sediment was freeze-dried and homogenized. Oxygen concentrations of the water column were measured by an SBE 43 dissolved oxygen sensor (Seabird, WA, USA) fitted to the CTD frame and calibrated against Winkler titrations. The limit of detection for these methods was $3 \mu \mathrm{mol} \mathrm{L} \mathrm{L}^{-1}$. Oxygen penetration depths were measured on board in $0.1 \mathrm{~mm}$ resolution using an OX-100 micro sensor (Unisense AS, Aarhus, DK) with a guard cathode as described by Revsbech (1989).

\subsection{Total organic carbon content and sedimentation rates}

Freeze-dried sediments were analyzed for total organic carbon content (TOC). One aliquot of freeze-dried sediments was acidified in situ with $2 \mathrm{~N} \mathrm{HCl}$ in silver cups to remove carbonates, thereby avoiding the loss of acid-soluble organic carbon. Another aliquot of freeze-dried sediment was acidified over night with $2 \mathrm{~N} \mathrm{HCl}$, subsequently washed with bidistilled $\mathrm{H}_{2} \mathrm{O}$ and freeze-dried. The decalcified sediments were measured on a Flash EA 1112 Series (Thermo Scientific) analyzer coupled via a Conflo II

Table 1

Locations and depths of the sampled surface cores, PASOM original station names in brackets.

\begin{tabular}{llc}
\hline Station name & Location & Depth $(\mathrm{m})$ \\
\hline P900 (station 1) & 22.54823N 64.03983E & 885 \\
P1300 (station 4) & 22.29993N 63.59980E & 1306 \\
P3000 (station 10) & 21.92877N 63.15823E & 3003 \\
\hline
\end{tabular}

interface to a Finnigan Delta ${ }^{\text {plus }}$ mass spectrometer. The organic carbon reported is an average of all (4-8) measurements, excluding outliers identified by a Grubbs Test. Standard deviations of replicate measurements ranged from $\pm 0.07 \%$ to $\pm 0.7 \%$ TOC with an average of \pm 0.4 for P900, $\pm 0.06 \%$ to $\pm 0.57 \%$ with an average of $\pm 0.3 \%$ for $\mathrm{P} 1300$ and $\pm 0.0004 \%$ to $\pm 0.06 \%$ with an average of $\pm 0.03 \%$ for P3000.

For ${ }^{14} \mathrm{C}$ dating, subsamples of parallel cores from the same multicore deployment were used. For each multicore deployment the top 1-2 cm, one subsample from the center of the core (P900: 19-20 cm, P1300: 11-12 cm, P3000: 10 $11 \mathrm{~cm}$ ) and one near the base of the multicore (P900: 39 $40 \mathrm{~cm}$, P1300 and 3000: $21-22 \mathrm{~cm}$ ) was used for dating. The ${ }^{14} \mathrm{C}$-age determinations were based on the carbonate from the tests of planktonic foraminiferal hand-picked from the 150 to $595 \mu \mathrm{m}$ size fraction. All available planktonic foraminiferal species were used due to the limited amount of material available (ranging from 4.5 to $28.8 \mathrm{mg}$ ). ${ }^{14} \mathrm{C}$ was measured using accelerated mass spectrometry at the Poznan radiocarbon laboratory. ${ }^{14} \mathrm{C}$-ages were subsequently corrected for reservoir age (400 yr) and calibrated to calendar ages using the Int09 calibration curve (CALIB software package, version 6.0.1). The two deeper samples were used to calculate the linear sedimentation rates, assuming the top sample to represent present day.

\subsection{Bligh-dyer extraction and IPL-CL separation}

Approximately $2 \mathrm{~g}$ (P1300 and P3000) and $1 \mathrm{~g}$ (P900) aliquots of freeze-dried sediment were extracted with a modified Bligh and Dyer procedure as described by Pitcher et al. (2009). Briefly, extraction with methanol $(\mathrm{MeOH}) /$ dichloromethane (DCM)/phosphate buffer (PB) $50 \mathrm{mM}$, $\mathrm{pH}$ 7.5, in volume ratios 2:1:0.8 was carried out three times by ultrasonication and the solvent was collected after centrifugation. The combined liquid phases were adjusted to a solvent ratio of $\mathrm{MeOH} / \mathrm{DCM} / \mathrm{PB}$ of 1:1:0.9 (v/v) which led to phase separation between the DCM and the $\mathrm{MeOH} / \mathrm{PB}$. The DCM phase was collected and the 
$\mathrm{MeOH} / \mathrm{PB}$ mixture was extracted twice more with DCM. The combined DCM phases were reduced with a rotary evaporator, re-dissolved in $\mathrm{DCM} / \mathrm{MeOH}$ 9:1 (v/v), filtered over cotton wool and subsequently dried under a stream of $\mathrm{N}_{2}$. The extract was stored at $-20^{\circ} \mathrm{C}$.

One aliquot of extract was directly analyzed by HPLC/ ESI-MS ${ }^{2}$ for intact polar lipids (IPL), while another aliquot was fractionated over a silica column in order to separate the IPL from the core lipids (CL) following the procedure of Oba et al. (2006) and Pitcher et al. (2009). Fractionation was achieved over a column with $0.8 \mathrm{~g}$ silica gel (60 mesh) activated at $130{ }^{\circ} \mathrm{C}$ overnight. Core lipids were eluted using $6 \mathrm{~mL}$ hexane/ethyl acetate $1: 1(\mathrm{v} / \mathrm{v})$ and intact polar lipids using $10 \mathrm{~mL} \mathrm{MeOH}$. The core lipid fractions were dried and $0.1 \mu \mathrm{g} \mathrm{C}_{46}$-GDGT internal standard (Huguet et al., 2006b) was added. To the intact polar lipid fractions $0.1 \mu \mathrm{g}$ internal standard was added and an aliquot of $3 \mathrm{~mL}$ was transferred to a vial, dried and stored frozen for quantification of core lipids which eluted in the intact polar lipid fraction ("carry over"). These were typically $<2 \%$ of the GDGTs present in CL fraction or $10 \%$ of GDGTs present in the IPL fraction. The remaining IPL fraction was dried and hydrolyzed for $3 \mathrm{~h}$ under reflux in $5 \%$ methanolic $\mathrm{HCl}$ to release CL-GDGTs. Bidistilled $\mathrm{H}_{2} \mathrm{O}$ was added and the $\mathrm{pH}$ was adjusted to 4-5 with methanolic $1 \mathrm{M} \mathrm{KOH}$, then the $\mathrm{MeOH} / \mathrm{H}_{2} \mathrm{O}$ ratio was adjusted to $1: 1(\mathrm{v} / \mathrm{v})$. The core lipids were extracted from the aqueous phase 3 times with DCM. The DCM phases were combined, the DCM was removed with a rotary evaporator, and the residue was re-dissolved in DCM and dried over $\mathrm{Na}_{2} \mathrm{SO}_{4}$. This yielded the IPL-derived CL fraction.

\subsection{HPLC/APCI-MS and HPLC/ESI-MS ${ }^{2}$}

Analysis of CL-GDGTs and IPL-derived GDGTs by HPLC/APCI-MS and calculation of $\mathrm{TEX}_{86}$ was carried out as described in the companion paper (Schouten et al., 2012). The average relative standard deviation for quantification of GDGTs, calculated from triplicate extractions of 1 (P1300) or 3 (P900, P3000) sediment samples, was 6\% (CL) and 10\% (IPL-derived) for P900, 11\% (CL) and 16\% (IPL-derived) for P1300 and 13\% (CL) and 21\% (IPL-derived) for $\mathrm{P} 3000$. Reproducibility for $\mathrm{TEX}_{86}$ values were typically $<0.01$, corresponding to errors of $<0.5^{\circ} \mathrm{C}$. Temperatures were calculated according to the $\mathrm{TEX}^{\mathrm{H}}{ }_{86}$ calibration (which is the log of $\mathrm{TEX}_{86}$ ) according to Kim et al. (2010).

Intact polar lipids, i.e. monohexose (MH)-crenarchaeol, dihexose (DH)-crenarchaeol and hexose, phosphohexose (HPH)-crenarchaeol, were directly analyzed by HPLC/ ESI-MS $^{2}$ using a specific selected reaction monitoring method (SRM; Pitcher et al., 2011). No absolute quantification was possible due to a lack of standards. Therefore, response areas (in arbitrary units, au) per g sediment are reported. Due to variation in MS performance over longer time periods, measurements are comparable down core as they were analyzed in batch runs, but not between cores which were measured at different times. An IPL fraction of Candidatus Nitrososphaera gargensis (Pitcher et al., 2010) was injected typically after 8 sample runs to monitor performance of the ESI-MS ${ }^{2}$ during batch runs. Standard deviations from triplicate extractions of sediment at $22 \mathrm{~cm}$ depth at P1300 were $8 \%$ area/g sediment dw for the monohexose-crenarchaeol and $20 \%$ area/g sediment $\mathrm{dw}$ for the dihexose-crenarchaeol.

\subsection{Semi-preparative HPLC}

For the isolation of particular IPL-GDGTs, repetitive preparative HPLC was used as described previously in Schouten et al. (2008). Bligh Dyer extracts of ca. $4 \mathrm{~g}$ of sediment from 0 to $2 \mathrm{~cm}$ depth ("top") and of $4 \mathrm{~g}$ of sediment from 20 to $24 \mathrm{~cm}$ depth ("bottom") from P1300 were separated on an Agilent (San Jose, CA, USA) 1100 series LC with an Inertsil diol column ( 250 by $10 \mathrm{~mm} ; 5 \mu \mathrm{m}$ particles; Alltech Associates Inc., Deerfield, IL) at a flow rate of $3 \mathrm{~mL} / \mathrm{min}$ and identical conditions as for intact polar lipids (see above and Pitcher et al., 2011). Fractions of $3 \mathrm{~mL}$ were collected and subsequently measured with Flow Injection Analysis using ESI-MS ${ }^{2}$ in SRM mode at the same conditions as the analytical SRM, monitoring the same transitions. Injection solvent was a mixture of $60 \% \mathrm{~A}$ and $40 \%$ B with A being hexane/isopropanol/formic acid/14.8 M aqueous $\mathrm{NH}_{3}$ (79:20:0.12:0.04, vol/vol/vol/vol) and B being isopropanol/water/formic acid/14.8 $\mathrm{M}$ aqueous $\mathrm{NH}_{3}$ (88:10:0.12:0.04, vol/vol/vol/vol). In the top sediment, three fractions, comprising monohexose-GDGTs, dihexoseGDGTs and hexose, phosphohexose-GDGTs respectively, were collected. The dihexose-GDGTs likely contained a minor amount of co-eluting GDGTs with a loss of $\mathrm{m} / \mathrm{z}$ 341 as observed in Candidatus Nitrosopumilus maritimus SCM1 (Schouten et al., 2008). From the bottom sediment sample, the monohexose- and dihexose-crenarchaeol fractions were collected while hexose, phosphohexose-crenarchaeol was not detected. The fractions containing the IPL-GDGTs were acid-hydrolyzed and the CL-GDGT distributions were quantified using HPLC/APCI-MS and the $\mathrm{C}_{46}$-GDGT internal standard method as described above.

\section{RESULTS}

\subsection{Oxygen concentrations, total organic carbon content (TOC) and sedimentation rates}

Sediment cores were taken at three stations: P900 was in the oxygen minimum zone (OMZ) at 885 mbss; P1300 was just below the OMZ at 1306 mbss, while P3000 was located at the foot of the Murray Ridge in oxygenated bottom waters at 3003 mbss (Fig. 2). The oxygen concentration of the bottom water of P900 was below detection limit $\left(<3 \mu \mathrm{mol} \mathrm{L}^{-1}\right)$, and of P1300 and P3000 at 14 and $83 \mu \mathrm{mol} \mathrm{L}{ }^{-1}$, respectively. Oxygen penetration depths measured on-board with microelectrodes were less than $0.125 \mathrm{~mm}$ at P900, $3 \mathrm{~mm}$ at $\mathrm{P} 1300$ and $18 \mathrm{~mm}$ at P3000.

The sediment core at P900 was composed of very dark olive-brown mud, uniform over the whole depth. In the cores at P1300 and P3000, a change in texture and color was observed. The core from P1300 had a distinct $1 \mathrm{~cm}$ red-brown layer on top, while that of P3000 was brown colored down to $7 \mathrm{~cm}$ depth, and then changed to gray with a 
clayish texture. The organic carbon content varied substantially between the three stations (Fig. 3). At P900, TOC ranged from $5 \%$ to $8 \%$ [organic carbon (g sediment $\mathrm{dw})^{-1}$ ], while it was $1.3-3 \%$ at $\mathrm{P} 1300$ and $\leqslant 1 \%$ at $\mathrm{P} 3000$. The profiles at P900 and P1300 showed little variation downcore (Fig. 3) but an increase in organic carbon content from $0.6 \%$ to $1 \%$ between 9 and $16 \mathrm{~cm}$ depth was observed at P3000.

${ }^{14} \mathrm{C}$-ages determined from planktonic foraminiferal shells (Table 2) showed an age offset between the ${ }^{14} \mathrm{C}$-age of the top sample and the reservoir age, due to ongoing bioturbation. Bioturbation depth could be estimated by multiplying the age of the top sediment (corrected for the reservoir age of $400 \mathrm{yr}$ ) with the sedimentation rate (Table 2). Average linear sedimentation rates were 8.5, 3.8 and $8.3 \mathrm{~cm} / \mathrm{kyr}$ for P900, P1300 and P3000, respectively, and mixing depths were 8.5 and $13-14 \mathrm{~cm}$ for P1300 and $\mathrm{P} 3000$. Sedimentation rates differed considerably between sites, which is probably due to the local topography. Values are, however, similar to what has been reported earlier for the same area: $13.3 \mathrm{~cm} / \mathrm{kyr}$ at $970 \mathrm{~m}$ water depth and $4.3 \mathrm{~cm} / \mathrm{kyr}$ at $1511 \mathrm{~m}$ water depth (van der Weijden et al., 1999). Bioturbation depths were also comparable to values reported earlier for the northernmost Arabian Sea (ibid.) and increased with increasing bottom water oxygenation. Pore water profiles, ${ }^{210} \mathrm{~Pb}$ dating and $\mathrm{Ti} / \mathrm{Ca}$ ratios of sediments from the same locations showed that sedimentation was relatively continuous with no evidence for winnowing or gravity flows (Kraal et al., 2012).

\subsection{Abundance and distribution of CL and IPL-derived GDGTs}

The concentrations of CL-GDGTs and the IPL-derived GDGTs were determined for crenarchaeol, GDGT-0, and the sum of GDGTs-1, $-2,-3$ and $-4^{\prime}$ which are used for determination of the $\mathrm{TEX}_{86}$ (Fig. 4). Total IPL- and CLGDGT-concentrations (the sum of all measured GDGTs) in the core from P900 ranged from 4 to $8 \mu \mathrm{g}$ (g sediment $\mathrm{dw})^{-1}$ for IPL-derived GDGTs and $60-110$ for CLGDGTs. These concentrations were one order of magnitude higher than in P1300 [(1-2 and 10-17 $\mu \mathrm{g}$ (g sediment $\mathrm{dw})^{-1}$ ] and two orders of magnitude higher than in P3000 [0.3-1.7 and $\left.1-7 \mu \mathrm{g}(\mathrm{g} \text { sediment } \mathrm{dw})^{-1}\right]$. IPL-derived GDGTs were always less abundant than CL-GDGTs and amounted to $5-15 \%$ of CL-GDGTs at P900, 5-15\% at $\mathrm{P} 1300$ and $10 \%$ at P3000 for crenarchaeol and the sum of GDGT-1, $-2,-3$ and -4 '. However, IPL-derived GDGT-0 showed a peak in concentration in the surface sediment of P3000 (Fig. 5c) and the highest percentage of IPL-derived/CL-concentrations in all three cores, particularly in the core from $\mathrm{P} 3000$, with almost $50 \%$ in the top horizon,

\begin{tabular}{rlllll}
\multicolumn{9}{c}{ TOC [\%] } & & \\
0 & 2 & 4 & 6 & 8 & 10 \\
\hline
\end{tabular}
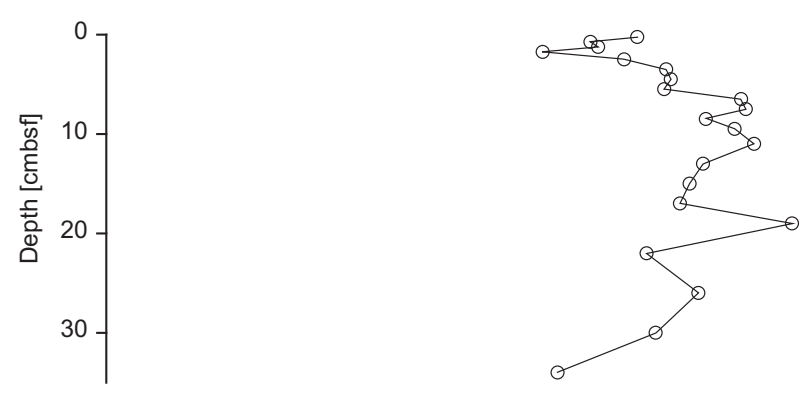

P900
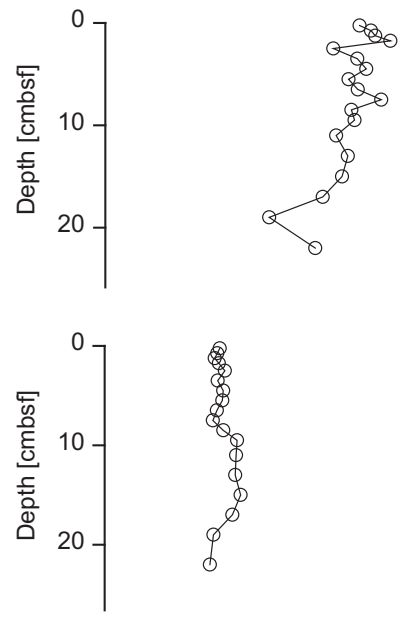

P3000

Fig. 3. Total organic carbon content (TOC) in $\%$ and accumulation rate of organic carbon per g dry weight of the three analyzed cores vs. depth in $\mathrm{cm}$ below sea floor. 
Table 2

Radiocarbon dating results. Medium ${ }^{14} \mathrm{C}$-age (minimum-maximum) in $\mathrm{yr}$ of foraminiferal test carbonate picked from respective depth intervals. Mix depth - mixing or bioturbation depth in $\mathrm{cm}$ below sea floor [cmbsf], sed rates - sedimentation rates. Reservoir age used was $400 \mathrm{yr}$.

\begin{tabular}{|c|c|c|c|c|}
\hline Station & Interval (cmbsf) & ${ }^{14} \mathrm{C}$-age (yr) & Mix depth (cmbsf) & Sed rates $\left(\mathrm{cm} \mathrm{kyr}^{-1}\right)$ \\
\hline \multirow[t]{3}{*}{ P900 } & $1-2$ & $88(18-145)$ & & \\
\hline & $19-20$ & $1207(1118-1282)$ & - & 8.5 \\
\hline & $39-40$ & $2941(2792-3078)$ & & \\
\hline \multirow[t]{3}{*}{ P1300 } & $1-2$ & $2233(2152-2280)$ & & \\
\hline & $11-12$ & $2920(2839-3042)$ & 8.5 & 3.8 \\
\hline & $21-22$ & $5524(5465-5622)$ & & \\
\hline \multirow[t]{3}{*}{ P3000 } & $1-2$ & 1735 (1611-1825) & & \\
\hline & $10-11$ & $1463(1375-1541)$ & 14.5 & 8.3 \\
\hline & $21-22$ & $2376(2310-2491)$ & & \\
\hline
\end{tabular}

and $25-35 \%$ in lower horizons of the core. Otherwise, there was relatively little variation in CL- and IPL-derived GDGT concentrations with depth at P900 and P1300. A threefold increase in concentration was observed at P3000 (Fig. 4), where a transient strong increase in CL-GDGTs concentrations between 8 and $18 \mathrm{~cm}$ and an overall increase with depth were apparent (Fig. 4c).

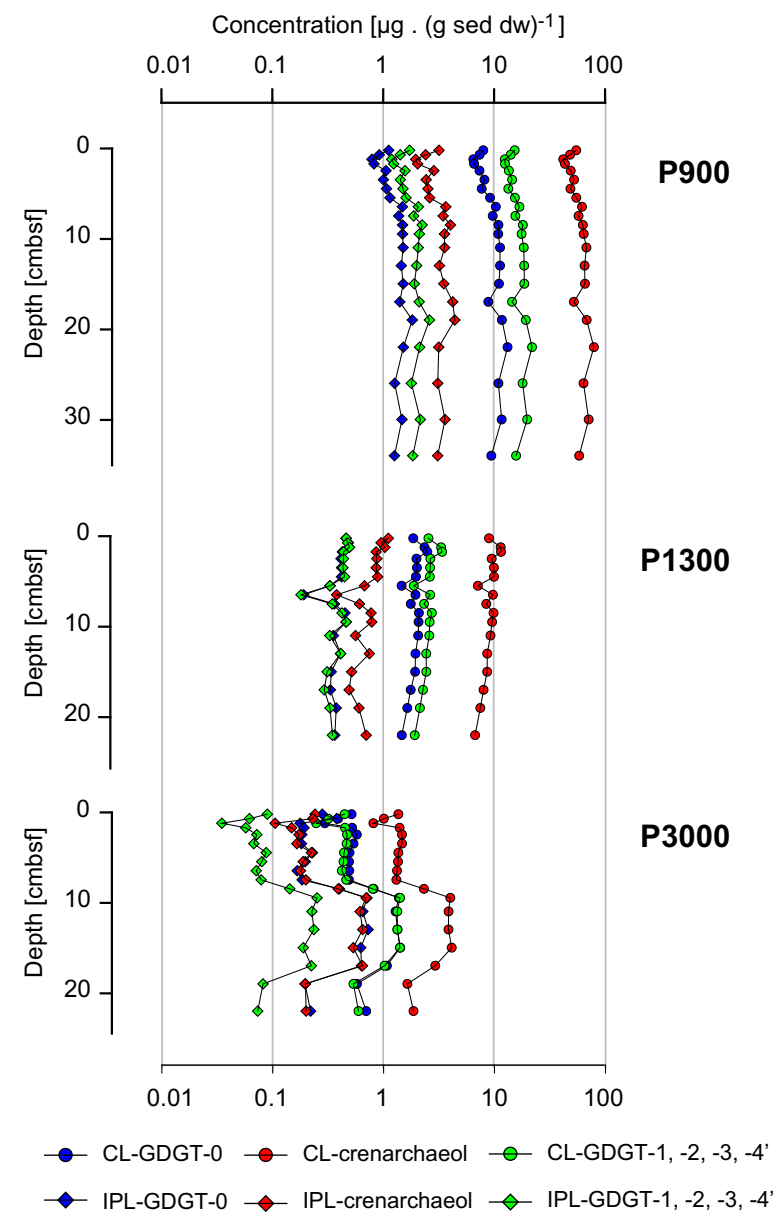

Fig. 4. Concentrations per g dry weight sediment and accumulation rates of crenarchaeol, GDGT-0 and the sum of GDGTs-1, -2, 3 and $-4^{\prime}$ for (a) P900, (b) P1300 and (c) P3000. Note the logarithmic scales of the $X$-axis.
$\mathrm{TEX}_{86}$ values calculated from the CL-GDGTs varied no more than 0.03 (corresponding to $1{ }^{\circ} \mathrm{C}$; Kim et al., 2010) with depth within the cores (Fig. 5). At P900 (Fig. 5a), they ranged from 0.79 to 0.76 and at $\mathrm{P} 1300$ from 0.77 to 0.73 , while the $\mathrm{TEX}_{86}$ values at $\mathrm{P} 3000$ did not change significantly with depth $(0.71 \pm 0.01)$. The $\mathrm{TEX}_{86}$ of IPL-derived GDGTs at P900 ranged from 0.77 to 0.80 , and from 0.75 to 0.78 at $\mathrm{P} 1300$. At $\mathrm{P} 3000$, there was a distinct minimum in the surface sediment with low IPL-derived $\mathrm{TEX}_{86}$ values (down to 0.65 ), coinciding with the maximum in IPL-derived GDGT- 0 concentration. The $\mathrm{TEX}_{86}$ of IPL-derived GDGTs was generally $0.01-0.04$ higher than the $\mathrm{TEX}_{86}$ of the core lipids, except in the surface sediments at P900 and P1300, where they were identical.

$\mathrm{TEX}_{86}$ values differed significantly between stations: the CL-GDGTs in the top layer of sediment had a TEX T6 $_{86}$ of 0.79 at P900, 0.76 at P1300 and 0.70 at P3000. Similar differences were also observed in the $\mathrm{TEX}_{86}$ values of the IPLderived GDGTs $(0.78,0.76$ and 0.72 , respectively). The average $\mathrm{TEX}_{86}$ values over the whole cores of the CLGDGTs were $0.77 \pm 0.01$ at $\mathrm{P} 900,0.74 \pm 0.01$ at $\mathrm{P} 1300$ and $0.71 \pm 0.01$ at P3000 and for the IPL-derived GDGTs $0.78 \pm 0.02,0.76 \pm 0.01$ and $0.71 \pm 0.02$.

\subsection{Direct analysis of IPLs with a crenarchaeol core}

The sediments were also analyzed directly for a number of IPL species containing crenarchaeol as the core lipid (Fig. 1). The three most abundant IPLs detected by this method were monohexose ( $\mathrm{MH})$-crenarchaeol, dihexose (DH)-crenarchaeol and hexose, phosphohexose (HPH)crenarchaeol. An IPL with a loss of $m / z 341$ as found by Sturt et al. (2004) and Lipp et al. (2008) was also present, but near detection limit in all cores and is therefore not shown in Fig. 6. The assay was developed for IPLs with crenarchaeol as a core lipid (Pitcher et al., 2011) and therefore GDGT-0, -1, -2 and -3 with IPL moieties were not measured, but we assume that the distribution of the crenarchaeol-IPL will provide insights on the general dynamics of IPL GDGTs in the three different sediment cores.

The depth profiles of the glycolipids $\mathrm{MH}$ - and $\mathrm{DH}-$ crenarchaeol differed from those of HPH-crenarchaeol (Fig. 6). In the cores from P900 and P1300, the glycolipids showed no particular trends with depth and remained relatively constant. At P3000, the glycolipid concentrations increased 


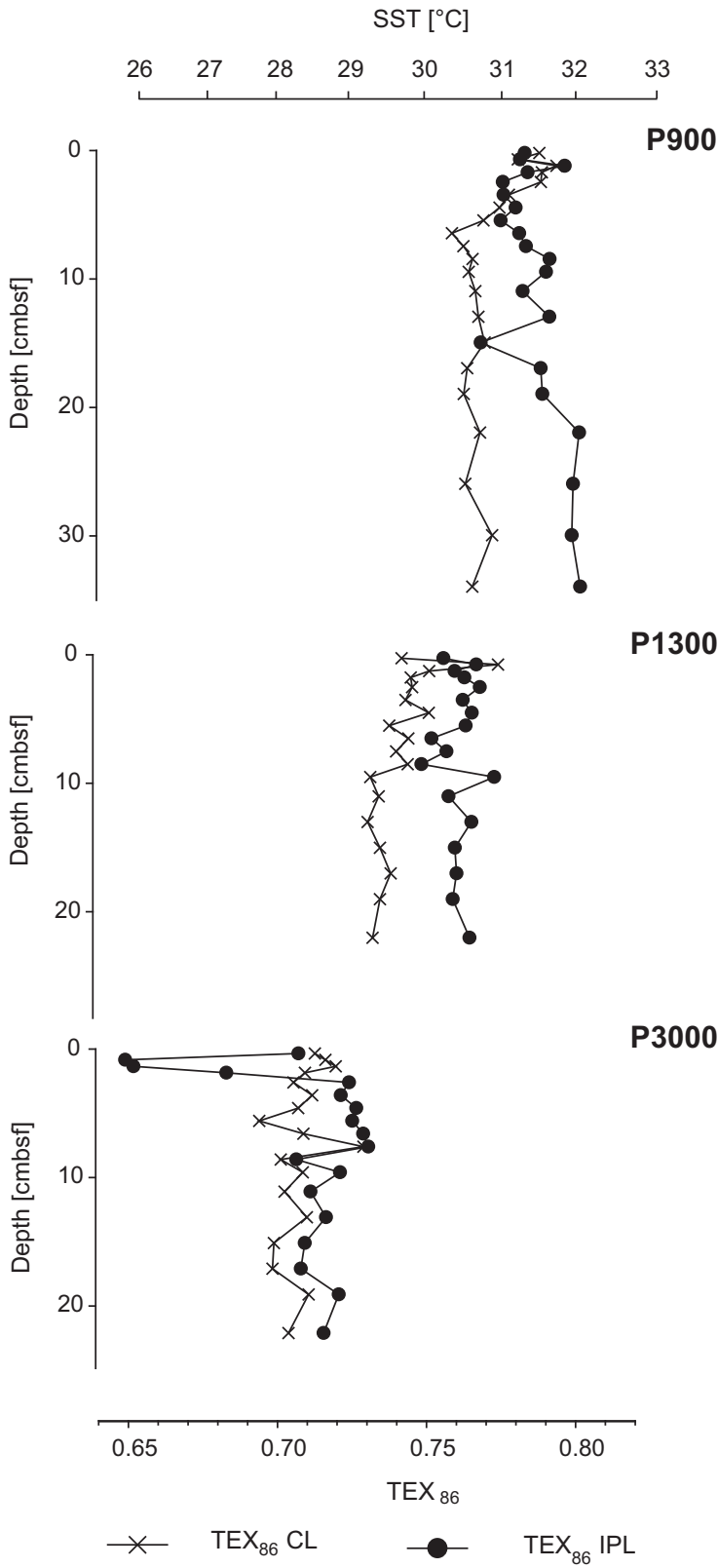

Fig. 5. TEX 86 values with depth for (a) P900 (b) P1300 and (c) P3000 well below the OMZ. The standard deviation is 0.01 units of TEX $_{86}$. The corresponding SST was calculated according to the global core top calibration (Kim et al., 2010) and is shown in the upper axis.

at the same depth interval where increases in TOC and IPLderived and CL GDGTs were measured. The HPH-crenarchaeol profiles at the different stations showed a strikingly different pattern compared to the glycolipids. While the HPH-crenarchaeol concentrations measured at P900 did not show significant trends with depth except for the deepest sediments (Fig. 6a), at P1300, just below the OMZ, its abundance decreased within $3 \mathrm{~cm}$ by more than one order of magnitude and then remained low and relatively variable (Fig. 6b). HPH-crenarchaeol at P3000 showed a similar but even more pronounced decrease by two orders of magni-

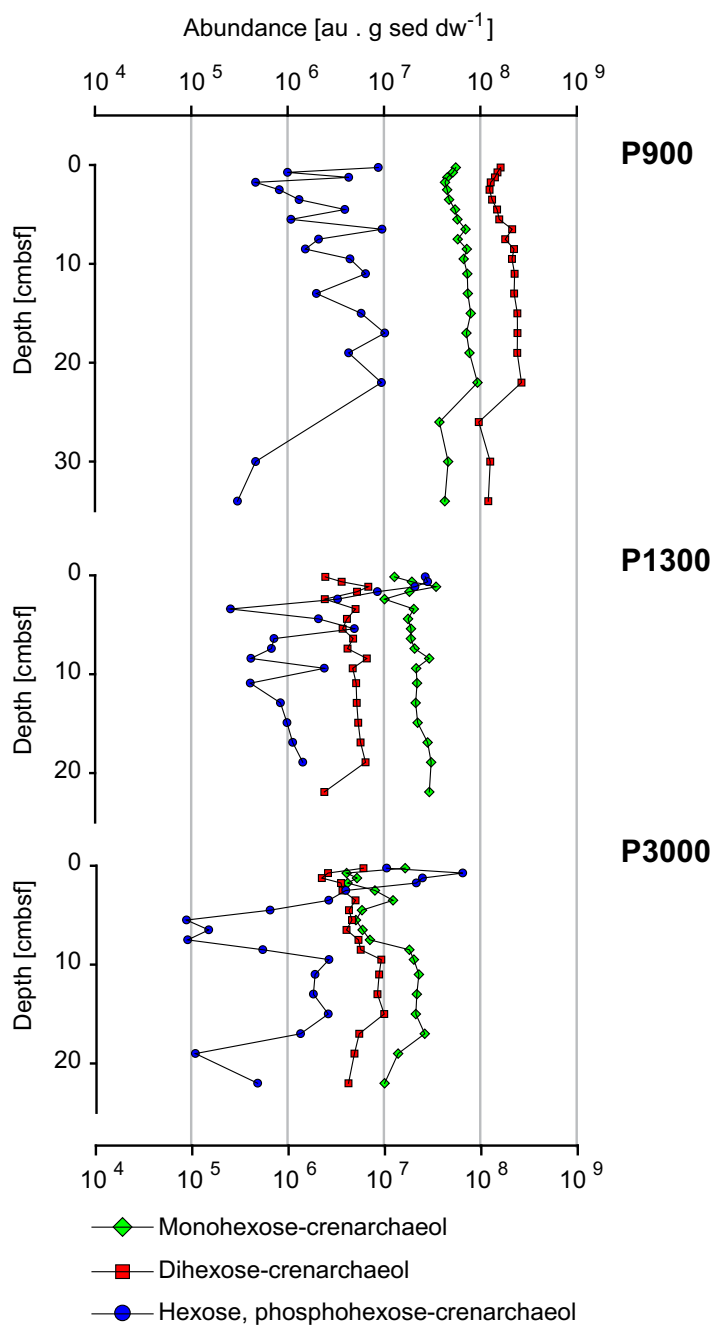

Fig. 6. Direct measurement of intact polar lipids monohexosecrenarchaeol, dihexose-crenarchaeol and hexose, phosphohexosecrenarchaeol by HPLC/ESI-MS ${ }^{2}$. (a) P900 (b) P1300 (c) P3000 well below the OMZ. Note the logarithmic scales of the $X$-axis.

tude from 1.25 to $5 \mathrm{~cm}$ (Fig. 6c). At this station, an increase in the HPH concentration was noted in the same interval where increases in TOC and IPL-derived and CL-GDGTs were observed (cf. Figs. 3c and 6c).

\subsection{Distribution of GDGTs in IPLs with different headgroups}

In order to determine the distributional variation in CLcomposition of the different intact polar lipid species, the IPL-GDGTs were isolated by semi-preparative HPLC from 0 to $2 \mathrm{~cm}$ and from 20 to $24 \mathrm{~cm}$ depth layers of the sediment core at P1300 and subsequently acid hydrolyzed and analyzed for GDGT distributions. While from the sediment at $0-2 \mathrm{~cm}$ depth, fractions containing $\mathrm{MH}-, \mathrm{DH}-$ and HPH-GDGTs were obtained, at 20-24 cm depth, only MH- and DH-GDGTs were present in high enough quantities (Fig. 7a). Fractions 10, 11 and 12 contained MHGDGTs, fractions 24 and 25, and in case of the 20-24 cm 
sample also fractions 23 and 26 contained DH-GDGTs and fractions 46 and $47 \mathrm{HPH}-$ GDGTs.

For both sediments, it was found that the DH-GDGTs, contained relatively more-GDGT-2, -3 and $4^{\prime}$ and less GDGT-1 as a core lipid than the MH-GDGTs and, in case of the top sediment, the HPH-GDGTs. This resulted in large differences in $\mathrm{TEX}_{86}$ values between the various types of IPL-GDGTs, i.e. 0.88 for the DH-GDGTs, 0.65 for the MH-GDGTs and 0.55 for the HPH-GDGTs (Fig. 7b).

\section{DISCUSSION}

\subsection{Sedimentary production and preservation of GDGTs}

IPL-GDGTs in the sediments can have two sources: water-column derived GDGTs (i.e. either from the water column directly above the sediment or laterally transported GDGTs), and GDGTs produced in situ by sedimentary Archaea (cf. Lipp and Hinrichs, 2009; Liu et al., 2011). Ammonia-oxidizing Archaea, whose IPLs consist mainly of GDGTs with MH-, DH- and HPH- as well as an unknown headgroup (Sinninghe Damsté et al., 2002b; Schouten et al., 2008; Pitcher et al., 2010, 2011), are ubiquitous and active in marine surface sediments (Francis et al., 2005; Caffrey et al., 2007; Park et al., 2008, 2010). Since archaeal ammonia-oxidation proceeds aerobically (Könneke et al., 2005; Hatzenpichler et al., 2008; Erguder et al., 2009; Park et al., 2010) and also in environments with low oxygen concentrations ranging from $<3 \mu \mathrm{M}$ to $0.2 \mathrm{mM}$, we expected in situ production of crenarchaeol-IPLs in (sub-) surface layers where low amounts of oxygen were still present, i.e. P1300 and P3000, and negligible production at P900, where oxygen hardly penetrated into the sediments. Indeed, pronounced (sub-) surface maxima of HPH-crenarchaeol, likely the most suitable tracer for living AOA (see Schouten et al., 2012), are observed in the cores from P1300 and P3000, where oxygen penetrated the sediments (Fig. 6), suggesting production by benthic aerobic AOA. This maximum is not observed in the sediment core at station P900, where oxygen hardly penetrates into the sediment. Indeed, it is remarkable that the HPH-crenarchaeol constituted on average $50 \%$ of the SRM area measured in SPM of the $>0.7 \mu \mathrm{m}$ size fraction (Fig. 8, cf. Schouten et al., 2012), while in the sediment underlying this water profile (station P900), the relative contribution of HPHcrenarchaeol to the total peak area is relatively low (ca. $4 \%$ ) both at the surface and at 20-24 cm depth (Fig. 8). Collectively, this indicates negligible benthic production of $\mathrm{HPH}$-crenarchaeol at station P900, in contrast to stations P1300 and P3000.

Sedimentary degradation of HPH-crenarchaeol seems to proceed in the first few $\mathrm{cm}$, and then ceases, suggesting two pools of HPH-crenarchaeol: a readily degradable pool, which is rapidly broken down $(<1-2 \mathrm{kyr})$, probably derived from in situ sedimentary production and therefore accessible for degradation, and a slowly degrading pool, likely fossil pelagic IPLs attached to the mineral matrix of particles and protected from degradation. The second, more resistant pool of HPH-crenarchaeol likely stems from the water column where IPL-GDGTs are found in $>0.7 \mu \mathrm{m}$ size SPM
$0-2 \mathrm{~cm}$

(a)

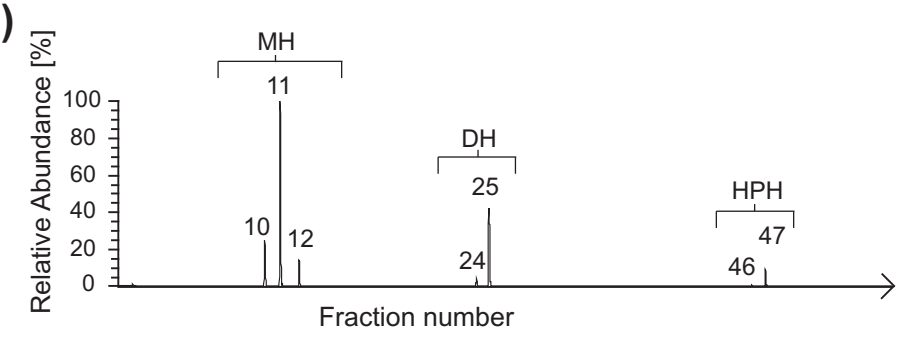

$20-24 \mathrm{~cm}$

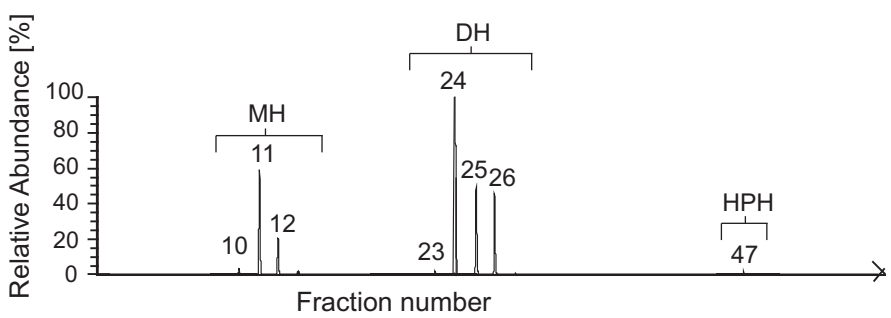

$0-2 \mathrm{~cm}$

(b)

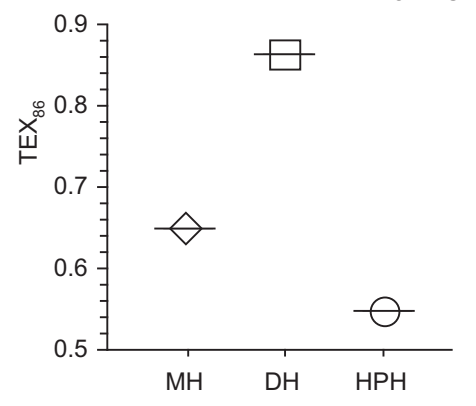

$20-24 \mathrm{~cm}$

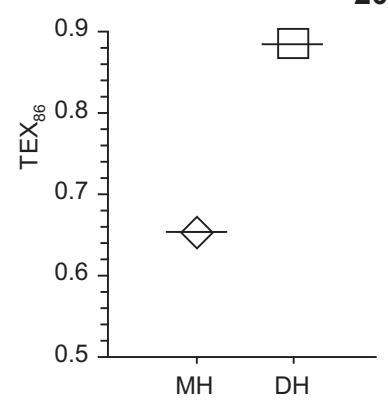

Fig. 7. (a) Relative total ion current (TIC) of the fractions obtained by semi-preparative HPLC of sediment from P1300, 0-2 and 20-24 core depth. Measured by flow injection analysis and SRM of the 1-min fractions. Types of main IPL contained are indicated. (b) TEX 86 values of the different IPL species (value of pooled fractions). MH, monohexose-GDGTs; DH, dihexose-GDGTs; HPH, hexose, phosphohexoseGDGTs from the top 2 and $20 \mathrm{~cm}$ depth. 


\begin{tabular}{|c|c|c|c|}
\hline SPM & \multicolumn{3}{|c|}{ Sediment } \\
\hline $170 \mathrm{~m} \quad 2000 \mathrm{~m}$ & $900 \mathrm{~m}$ & $1300 \mathrm{~m}$ & $3000 \mathrm{~m}$ \\
\hline & $0-0.5 \mathrm{~cm} 20-24 \mathrm{~cm}$ & $0-0.5 \mathrm{~cm} 20-24 \mathrm{~cm}$ & $0-0.5 \mathrm{~cm} 20-24 \mathrm{~cm}$ \\
\hline
\end{tabular}

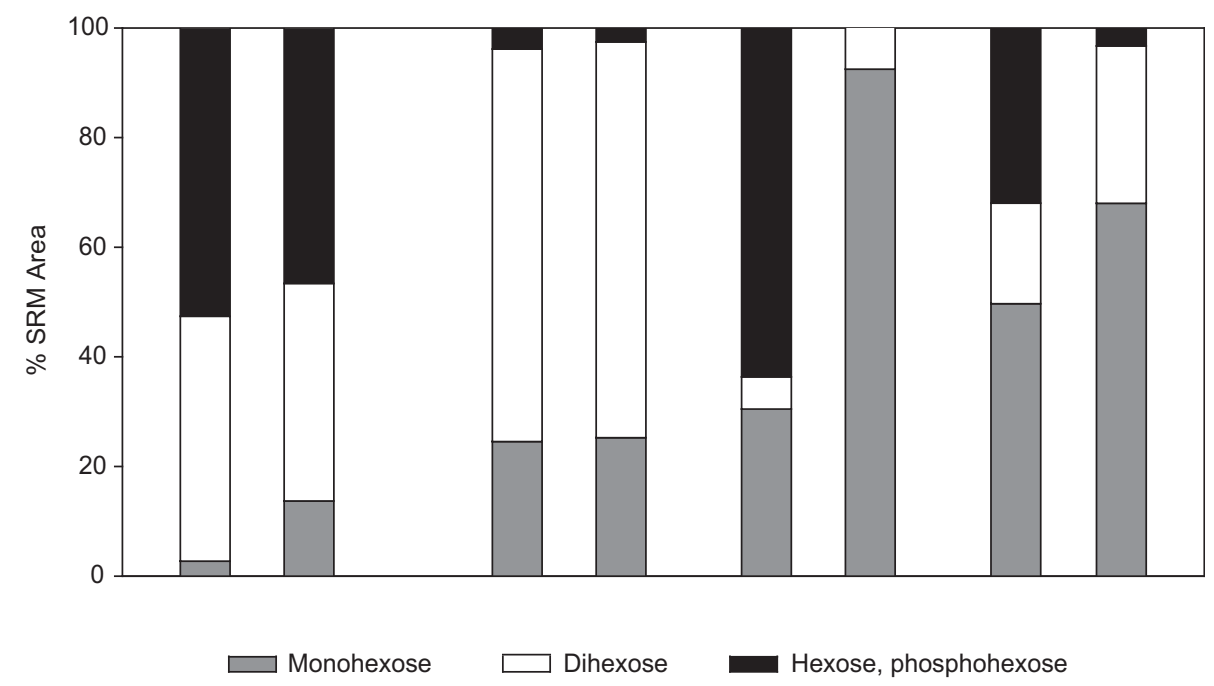

Fig. 8. \% of SRM peak area of monohexose-, dihexose and hexose, phosphohexose-crenarchaeol in SPM at 170 and $2000 \mathrm{~m}$ water column depth (Schouten et al., 2012) and from the top 0.5 and 20-24 cm sediment depth at P900, P1300 and P3000.

(Schouten et al., 2012), where they are probably being protected from degradation by adsorption to particles and into mesopores (Mayer, 1994; Hedges and Keil, 1995; Mayer et al., 2004). The rapid decrease of the HPH-crenarchaeol below the surface sediment production peak at stations P1300 and P3000 and the relatively low amounts of HPH crenarchaeol at station P900, are in accordance with the rapid degradation kinetics for phosphoester-lipids found by Harvey et al. (1986). Furthermore, the resemblance of the HPH-crenarchaeol concentration profile to the TOC profile below $7 \mathrm{~cm}$ depth at station P3000 suggests that increased preservation, indicated by the higher TOC values, results in high amounts of HPH-crenarchaeol, again indicating its probable origin from the water column.

In contrast, $\mathrm{MH}$ - and $\mathrm{DH}$-crenarchaeol profiles did not show any significant peaks in the surface sediment, which could either mean their production was occurring - to the same degree - at all depths, including anoxic zones, or that they are degraded so slowly that the majority of them is fossil and derived from the water column where they are abundantly present (Schouten et al., 2012). Recent studies in the Arabian Sea water column support the latter hypothesis: only the HPH-crenarchaeol concentration profile matched the archaeal amoA gene transcript abundance (Pitcher et al., 2011), whereas MH- and, to a lesser degree, DH-crenarchaeol concentrations showed disparate profiles (Schouten et al., 2012). The MH- and DH-crenarchaeol in sediments showed no decrease at all with depth, confirming the slow degradation rates, i.e. $>10 \mathrm{kyr}$, the timeframe covered by our cores, as theoretically predicted (Schouten et al., 2010). The strong resemblances of MH- and DH-profiles to those of TOC are indicating their pelagic provenance. Small amounts of $\mathrm{MH}$ - and $\mathrm{DH}$-crenarchaeol are likely also produced in the surface sediment, but, other than with $\mathrm{HPH}-c r e n a r c h a e o l$, these in situ produced $\mathrm{MH}$ - and DH-crenarchaeol amounts must be relatively minor compared to the fossil amounts of preserved pelagic $\mathrm{MH}-$ and DH-crenarchaeol. Our results thus suggest that (i) glycolipids are mainly derived from the water column, (ii) HPHcrenarchaeol is relatively rapidly degraded and (iii) benthic AOA are actively producing IPL-crenarchaeol in the (sub)surface of the sediment underneath the OMZ, probably occupying a low oxygen niche (cf. Chen et al., 2008; Abell et al., 2011; Pitcher et al., 2011). Interestingly, while the $\mathrm{HPH}$-crenarchaeol shows subsurface maxima indicating in situ production, the ratio of IPL-derived vs. CL-crenarchaeol does not increase as perhaps would be expected (Fig. 4). The amount of IPL-derived crenarchaeol, which represents the sum of all IPLs with crenarchaeol as a core lipid, is thus seemingly unaffected by the changes in $\mathrm{HPH}$-crenarchaeol concentration. The reason for this could be an analytical bias, as the $\mathrm{SiO}_{2}$ column used to isolate IPL-derived GDGTs selectively retains or degrades phospho-GDGTs but not glyco-GDGTs (Lengger et al., 2012). Thus, an increase in abundance in the phospho-GDGTs would not be readily visible in the IPL-derived GDGT fraction. Alternatively, the IPL-GDGTs are mainly composed of glycolipid GDGTs with low amounts of phospholipid GDGT and thus the total concentration in IPL-derived GDGTs is mainly determined by the amount of glycolipid GDGTs.

A notable exception to the general trend is the high abundance of IPL-derived GDGT-0 in the in the surface sediment of P3000 core (located in oxic bottom waters), possibly from benthic Archaea other than Thaumarchaeota, i.e. Eury- or Crenarchaeota. Importantly, however, the amount of CL-GDGT-0 is not simultaneously increasing; suggesting that also the in situ produced 
IPL-derived GDGT-0 is not affecting the CL-pool to a significant degree. IPL-GDGTs that are produced in situ are probably more vulnerable to microbial degradation as they may not be strongly absorbed to the sedimentary matrix and are therefore more readily degraded. Similarly, Liu et al. (2011) observed no transfers between the CL- and IPL-pool of GDGTs, except in sulfate-methane transition zones. Indeed, changes in CL distributions reflecting input of sedimentary methane-oxidizing Euryarchaeota have been observed in other sulfate-methane transition zones (e.g. Pancost et al., 2001; Weijers et al., 2011). These zones likely contain highly active archaeal communities which are productive over prolonged time periods, in an anoxic environment and thus slower degradation kinetics. Hence, at sites with high archaeal abundance and activity over prolonged time periods, the GDGTs produced in situ may eventually affect the composition of the fossil pool of pelagic GDGTs, while at other sites, this does not seem to be the case. The higher concentrations of IPL-derived GDGTs measured in the core from P3000 at 9-16 cm depth, however, are most likely not due to in situ production. The increase is, unlike the peak in the surface sediments, accompanied by a similar increase in organic carbon and CL-GDGT concentrations, with no change in CL-distribution and hence most likely due to higher accumulation rates or potentially bioturbation activity.

The organic carbon content as well as the amounts of GDGTs preserved in the sediment varied strongly with the oxygen concentrations of the bottom water (cf. Sinninghe Damsté et al., 2002a). The organic carbon content of sediment recovered from the OMZ (P900) was 2-3 times higher than in sediments recovered from below the OMZ. CL- as well as IPL-derived GDGT concentrations were 1-2 orders of magnitude higher at P900 than at P1300 and P3000. IPL-derived GDGTs amounted to 5-20\% of total GDGTs, with percentages of IPL-derived GDGTs increasing from P900 to P3000. The strong increase of both IPL-derived and CL-GDGT abundance with TOC is in agreement with the behavior of other biomarkers, as revealed previously in studies addressing oxic degradation of biomarkers (e.g. Prahl et al., 1997; Hoefs et al., 2002; Sinninghe Damsté et al., 2002a) and suggests that preservation of IPL GDGTs is also strongly dependent on oxygen exposure times.

\subsection{Implications for the $\mathrm{TEX}_{86}$ paleothermometer}

The $\mathrm{TEX}_{86}$ of the IPL-GDGTs did not differ in general from the respective $\mathrm{CL}-\mathrm{TEX}_{86}$ by more than 0.03 units (corresponding to ca. $1^{\circ} \mathrm{C}$, within the calibration error of $2{ }^{\circ} \mathrm{C}$, Kim et al., 2010) within the three core locations (Fig. 5). Nevertheless, the TEX $_{86}$ of IPL-derived GDGTs was consistently higher than that of the CL-GDGTs, which has been observed previously in other settings (Schubotz et al., 2009; Lipp and Hinrichs, 2009). In particular, Liu et al. (2011) reported a consistently higher $\mathrm{TEX}_{86}$ of IPLderived GDGTs than of CL-GDGTs for a large variety (in depth as well as age) of marine sediments and a large range of $\mathrm{TEX}_{86}$ values. Their observations on longer timescales $(>100 \mathrm{kyr})$ agree well with our short-timescale observations ( $<10 \mathrm{kyr})$. The $\mathrm{TEX}_{86}$ values of the individual IPL-GDGTs, obtained by preparative HPLC, provide an explanation for this phenomenon. These show that HPHGDGTs have a substantially lower $\mathrm{TEX}_{86}$-value than that of IPL-derived GDGTs, whereas MH-GDGTs have a similar $\mathrm{TEX}_{86}$ and DH-GDGTs a comparatively high $\mathrm{TEX}_{86}$. These different $\mathrm{TEX}_{86}$ values of the different IPLs are likely already biosynthetically determined in Thaumarchaeota, since Schouten et al. (2008) and Pitcher et al. (2011) reported that GDGT-1 is mainly associated with the HPHIPLs while GDGT-2, -3 and -4 are mainly associated with the DH-headgroup in (enrichment) cultures of Thaumarchaeota. A more rapid lysis of the HPH-GDGTs, as observed in this study and that of Schouten et al. (2012), will preferentially remove GDGT-1 from the pool of IPLGDGTs and bring it into the pool of CL-GDGTs. This process would result in increasing $\mathrm{TEX}_{86}$ values of the IPL-pool, which then mainly consists of $\mathrm{MH}-$ and $\mathrm{DH}$ GDGTs, and a reduction of the $\mathrm{TEX}_{86}$ value of CLGDGTs. Indeed, studies reporting high $\mathrm{TEX}_{86}$ values of IPL-derived GDGTs relative to CL-GDGTs also report high abundance of DH-GDGTs (Lipp and Hinrichs, 2009; Schubotz et al., 2009), consistent with this explanation. Furthermore, discrimination against the labile and "sticky" HPH-lipids during extraction and work-up (Pitcher et al., 2009, in press; Lengger et al., 2012) could also cause a higher $\mathrm{TEX}_{86}$ of the GDGTs in the IPL fraction.

Our results also explain the observations of Liu et al. (2011) that, in eight different settings, TEX $_{86}$ of IPL-derived GDGTs was strongly correlated with the $\mathrm{TEX}_{86}$ values of CL-GDGTs $\left(R^{2}=0.68\right)$ even if in situ temperatures differed largely from SST. These authors suggested that both pools were connected because benthic Archaea would recycle the biphytanyl-chains contained in fossil core lipids when producing IPL-GDGTs as a means to decrease energy requirements. This hypothesis, however, does not explain the slightly higher $\mathrm{TEX}_{86}$ of the IPL-derived GDGTs compared to the CL-GDGTs, as an exchange of biphytanyl chains between both pools would ultimately lead to convergent $\mathrm{TEX}_{86}$ values. Furthermore, as shown in the companion paper (Schouten et al., 2012), the same offset between TEX $_{86}$ values of CL- and IPL-derived GDGTs was already observed in the water column where Thaumarchaeota are presumably actively synthesizing membrane lipids themselves. Thus, it is likely that a large part of the IPL-GDGTs in sediments is derived from fossil pelagic GDGTs and is not produced in situ. The similar observations by Liu et al. indicate that this is a general observation that can be applied to other marine settings.

Only at station P3000 at 0-2 cm depth, in situ production was high enough to change the $\mathrm{TEX}_{86}$ of the IPL-derived GDGTs, but the $\mathrm{TEX}_{86}$ signal of the CL-GDGTs does not reflect this change. This indicates that, as discussed above, in situ produced IPL-GDGTs are likely degraded quickly and do not accumulate as core lipids, probably due to a lack of matrix protection leading to rapid microbial degradation of the IPLs (Mayer, 1994; Huguet et al., 2008).

While we could not detect a strong effect on the TEX 86 by benthic in situ production of GDGTs, a consistent 
decrease in $\mathrm{TEX}_{86}$ was observed in sediments, but also, as shown in the companion paper (Schouten et al., 2012), in suspended particulate matter (SPM) with increasing water depth at which the sediment cores were retrieved from. For the core lipids, $\mathrm{TEX}_{86}$ decreased from 0.79 for sediments and 0.78 for SPM in the OMZ $(900 \mathrm{~m})$ to 0.71 for the sediments and 0.66 for the water column SPM in the oxic bottom waters (2000 and $3000 \mathrm{~m}$, respectively, Fig. 9). These $\mathrm{TEX}_{86}$ values correspond to $31.5-28.0^{\circ} \mathrm{C}$ using the Kim et al. (2010) calibration, while the mean annual sea surface temperature was $26.4^{\circ} \mathrm{C}$ (Wuchter et al., 2006). Similar decreases from 0.81 to 0.65 (water column SPM) and 0.79 to 0.68 (surface sediment) were observed for the IPLs. Interestingly, the $\mathrm{TEX}_{86}$ values of CL-GDGTs in sediment traps from the Arabian Sea also decrease from $450 \mathrm{~m}$ depth downwards (Wuchter et al., 2006). The apparent decreasing trend in sedimentary $\mathrm{TEX}_{86}$ values with increasing water depth could be due to several reasons: (i) preferential degradation of certain CL-GDGTs; (ii) sedimentary in situ production; (iii) contribution from Archaea in the deeper water column. The preferential diagenesis of certain core lipids can be discarded as a hypothesis, as the difference in $\mathrm{TEX}_{86}$ also occurs with IPL-derived GDGTs in the water column and in sediments. Regarding the second hypothesis, as discussed above, sedimentary in situ production is unlikely to significantly affect $\mathrm{TEX}_{86}$ values in surface sediments. Thus, the most likely explanation may be the incorporation of a signal from the lower, colder, part of the water column. This would be consistent with Pearson et al. (2001) and Shah et al. (2008) who found ${ }^{14} \mathrm{C}$-depleted GDGTs in Santa Monica Basin sediments, inferring provenance from deeper water horizons. Furthermore, Ingalls et al. (2006) found evidence for deep water production based on ${ }^{14} \mathrm{C}$-depleted values of GDGTs in the water column in the Pacific Ocean. The incorporation of a GDGT signal from deeper waters raises the question how well the $\mathrm{TEX}_{86}$ is reflecting surface water conditions. Indeed, several studies have shown that $\mathrm{TEX}_{86}$ is frequently not reflecting surface but subsurface $(0-200 \mathrm{~m})$ conditions (cf. Huguet et al., 2007; Lopes dos Santos et al., 2010). Kim et al. (2008) has shown that the correlation of $\mathrm{TEX}_{86}$ with 0 $200 \mathrm{~m}$ temperatures is similarly high as with SST. This correlation, however, strongly decreases with depth, suggesting there is no substantial deep water component. While there is a significant shift in $\mathrm{TEX}_{86}$ value corresponding to ca. $3{ }^{\circ} \mathrm{C}$, the shift is relatively small considering that the potential GDGT pool is increasing from $0-900 \mathrm{~m}$ to $0-3000 \mathrm{~m}$, i.e. tripling in size. This suggests that although there may be an addition of deep water GDGTs, this amount may be relatively small compared to that of the upper part $(0$ $200 \mathrm{~m}$ ) of the water column.

In summary, the $\mathrm{TEX}_{86}$ is likely not strongly affected by benthic in situ production in normal marine settings. However, the differential degradation of IPL-GDGTs we observed could potentially have an impact on $\mathrm{TEX}_{86}$ calibration studies. Methods used for $\mathrm{TEX}_{86}$ calibrations and paleotemperature assessment are based on the analysis of CL-GDGTs. Faster degradation of the HPH-GDGTs and the more slowly progressing transfer of the $\mathrm{MH}$ - and DH-GDGTs to the CL-pool could potentially lead to lower $\mathrm{TEX}_{86}$ values of CL in surface sediments than in deeper sediments. Calibration studies have so far relied on CLGDGTs in surface sediments, while paleoclimate studies measure $\mathrm{TEX}_{86}$ values in deeper, older horizons, where potentially also some MH- and DH-GDGTs have been transformed to CL-GDGTs, thereby slightly increasing TEX $_{86}$ values. However, since IPL-derived GDGTs are relatively minor compared to CL GDGTs $(<10 \%)$ this process likely leads to only slight overestimations of past SST.

\section{CONCLUSION}

Our study of sediments from the Arabian Sea deposited under contrasting oxygen conditions suggests that IPL-derived GDGTs, in particularly glycolipids, stemming from the water column are likely preserved in sediments and that their degradation is dependent on oxygen exposure time. Phospholipid-GDGTs are produced in oxic surface layers of sediment, probably by benthic AOA, but rapidly degrade within less than 1 or $2 \mathrm{kyr}$, while the amount of glycolipidGDGTs hardly changes. Additional evidence from concentrations of IPL-derived and CL-GDGTs and their TEX T6 $_{86}$ values shows that in situ production in the surface sediment does not substantially influence the $\mathrm{TEX}_{86}$ of the CL because it is either too small in amount compared to the fossil GDGTs or it is completely degraded quickly and not transferred into the CL-pool. Differences between $\mathrm{TEX}_{86}$ values of IPL-derived GDGTs and CL-GDGTs are likely due to

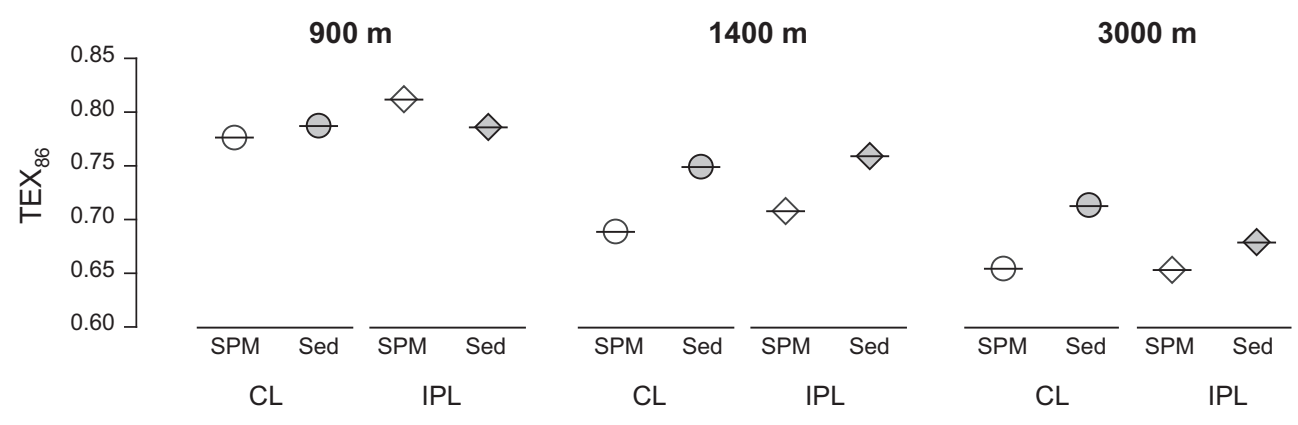

Fig. 9. TEX 86 values of SPM in the Arabian Sea water column (WC; from Schouten et al. (2012)) and of surface sediments on the Murray Ridge. Water depths were 900, 1400 (1350 m for SPM) and $3000 \mathrm{~m}$ (2000 m for SPM). CL, core lipids; IPL, intact polar lipids. 
differences between TEX $_{86}$ values of phospholipids and glycolipids and their dissimilar degradation rates. The average $\mathrm{TEX}_{86}$ for IPL-derived as well as CL decreased with increasing water depth, possibly due to the incorporation of a lower water column signal.

\section{ACKNOWLEDGMENTS}

We would like to thank the Master and the crew of the R/V Pelagia as well as the technicians and scientists participating in cruise 64PE301 for assistance during sampling. We also thank J. Ossebaar and S. Crayford for support with the LC/MS and TOC measurements, respectively. K. Koho kindly provided the data for the oxygen penetration depths. The PASOM cruise was funded by the Netherlands Organization for Scientific Research, NWO, by providing grant 817.01 .015 to G.J.R. This is publication number DW-2011-1009 of the Darwin Center for Biogeosciences, which partially funded a studentship (S.K.L.) by providing a grant to S.S.

\section{REFERENCES}

Abell G. C. J., Banks J., Ross D. J., Keane J. P., Robert S. S., Revill A. T. and Volkman J. K. (2011) Effects of estuarine sediment hypoxia on nitrogen fluxes and ammonia oxidizer gene transcription. FEMS Microbiol. Ecol. 75, 111-122.

Agogué H., Brink M., Dinasquet J. and Herndl G. J. (2008) Major gradients inputatively nitrifying and non-nitrifying Archaea in the deep North Atlantic. Nature 456, 788-791.

Beman J. M. and Francis C. A. (2006) Diversity of ammoniaoxidizing Archaea and bacteria in the sediments of a hypernutrified subtropical estuary: Bahía del Tóbari, Mexico. Appl. Environ. Microbiol. 72, 7767-7777.

Biddle J. F., Lipp J. S., Lever M. A., Lloyd K. G., Sørensen K. B., Anderson R., Fredricks H. F., Elvert M., Kelly T. J., Schrag D. P., Sogin M. L., Brenchley J. E., Teske A., House C. H. and Hinrichs K.-U. (2006) Heterotrophic Archaea dominate sedimentary subsurface ecosystems off Peru. Proc. Natl. Acad. Sci. USA 103, 3846-3851.

Bijl P. K., Schouten S., Sluijs A., Reichart G.-J., Zachos J. C. and Brinkhuis H. (2009) Early Palaeogene temperature evolution of the southwest Pacific Ocean. Nature 461, 776-779.

Brochier-Armanet C., Boussau B., Gribaldo S. and Forterre P. (2008) Mesophilic crenarchaeota: proposal for a third archaeal phylum, the Thaumarchaeota. Nat. Rev. Microbiol. 6, 245-252.

Caffrey J. M., Bano N., Kalanetra K. and Hollibaugh J. T. (2007) Ammonia oxidation and ammonia-oxidizing bacteria and archaea from estuaries with differing histories of hypoxia. Int. Soc. Microb. Ecol. 1, 660-662.

Cavicchioli R. (2006) Cold-adapted archaea. Nat. Rev. Microbiol. 4, 331-343.

Chen X.-P., Zhu Y.-G., Xia Y., Shen J.-P. and He J.-Z. (2008) Ammonia-oxidizing archaea: important players in paddy rhizosphere soil? Environ. Microbiol. 10, 1978-1987.

Coolen M. J. L., Abbas B., van Bleijswijk J., Hopmans E. C., Kuypers M. M. M., Wakeham S. G. and Sinninghe Damsté J. S. (2007) Putative ammonia-oxidizing Crenarchaeota in suboxic waters of the Black Sea: a basin-wide ecological study using $16 \mathrm{~S}$ ribosomal and functional genes and membrane lipids. Environ. Microbiol. 9, 1001-1016.

de la Torre J. R., Walker C. B., Ingalls A. E., Könneke M. and Stahl D. A. (2008) Cultivation of a thermophilic ammonia oxidizing archaeon synthesizing crenarchaeol. Environ. Microbiol. 10, 810-818.

de Rosa M. and Gambacorta A. (1988) The lipids of archaebacteria. Prog. Lipid Res. 27, 153-175.
DeLong E. F. (1992) Archaea in coastal marine environments. Proc. Natl. Acad. Sci. USA 89, 5685-5689.

DeLong E. F., King L. L., Massana R., Cittone H., Murray A., Schleper C. and Wakeham S. G. (1998) Dibiphytanyl ether lipids in nonthermophilic Crenarchaeotes. Appl. Environ. Microbiol. 64, 1133-1138.

Erguder T. H., Boon N., Wittebolle L., Marzorati M. and Verstraete W. (2009) Environmental factors shaping the ecological niches of ammonia-oxidizing archaea. FEMS Microbiol. Rev. 33, 855-869.

Forster A., Schouten S., Baas M. and Sinninghe Damsté J. S. (2007) Mid-Cretaceous (Albian-Santonian) sea surface temperature record of the tropical Atlantic Ocean. Geology 35, 919-922.

Francis C. A., Roberts K. J., Beman J. M., Santoro A. E. and Oakley B. B. (2005) Ubiquity and diversity of ammoniaoxidizing archaea in water columns and sediments of the ocean. Proc. Natl. Acad. Sci. USA 102, 14683-14688.

Fuhrman J. A., McCallum K. and Davies A. A. (1992) Novel major archaebacterial group from marine plankton. Nature 356, 148-149.

Gabriel J. L. and Chong P. L. G. (2000) Molecular modeling of archaebacterial bipolar tetraether lipid membranes. Chem. Phys. Lipids 105, 193-200.

Gliozzi A., Rolandi R., de Rosa M. and Gambacorta A. (1983) Monolayer black membranes from bipolar lipids of archaebacteria and their temperature-induced structural changes. $J$. Membr. Biol. 75, 45-56.

Harvey H. R., Fallon R. D. and Patton J. S. (1986) The effect of organic matter and oxygen on the degradation of bacterial membrane lipids in marine sediments. Geochim. Cosmochim. Acta 50, 795-804.

Hatzenpichler R., Lebedeva E. V., Spieck E., Stoecker K., Richter A., Daims H. and Wagner M. (2008) A moderately thermophilic ammonia-oxidizing crenarchaeote from a hot spring. Proc. Natl. Acad. Sci. USA 105, 2134-2139.

Hedges J. I. and Keil R. G. (1995) Sedimentary organic matter preservation: an assessment and speculative synthesis. Mar. Chem. 49, 81-115.

Herndl G. J., Reinthaler T., Teira E., van Aken H., Veth C., Pernthaler A. and Pernthaler J. (2005) Contribution of Archaea to total prokaryotic production in the deep Atlantic Ocean. Appl. Environ. Microbiol. 71, 2303-2309.

Hoefs M. J. L., Rijpstra W. I. C. and Sinninghe Damsté J. S. (2002) The influence of oxic degradation on the sedimentary biomarker record I: evidence from Madeira Abyssal Plain turbidites. Geochim. Cosmochim. Acta 66, 2719-2735.

Huguet C., Cartes J. E., Sinninghe Damsté J. S. and Schouten S. (2006a) Marine crenarchaeotal membrane lipids in decapods: implications for the TEX86 paleothermometer. Geochem. Geophys. Geosyst. 7, 1-12.

Huguet C., Hopmans E. C., Febo-Ayala W., Thompson D. H., Sinninghe Damsté J. S. and Schouten S. (2006b) An improved method to determine the absolute abundance of glycerol dibiphytanyl glycerol tetraether lipids. Org. Geochem. 37, 1036-1041.

Huguet C., Kim J.-H., Sinninghe Damsté J. S. and Schouten S. (2006c) Reconstruction of sea surface temperature variations in the Arabian Sea over the last $23 \mathrm{kyr}$ using organic proxies $\left(\mathrm{TEX}_{86}\right.$ and $\left.\mathrm{U}^{\mathrm{K}^{\prime} 37}\right)$. Paleoceanography 21, PA3003.

Huguet C., Schimmelmann A., Thunell R., Lourens L. J., Sinninghe Damsté J. S. and Schouten S. (2007) A study of the TEX86 paleothermometer in the water column and sediments of the Santa Barbara Basin, California. Paleoceanography 22, PA3203.

Huguet C., de Lange G. J., Gustafsson Ö., Middelburg J. J., Sinninghe Damsté J. S. and Schouten S. (2008) Selective 
preservation of soil organic matter in oxidized marine sediments (Madeira Abyssal Plain). Geochim. Cosmochim. Acta 72, 6061-6068.

Huguet C., Urakawa H., Martens-Habbena W., Truxal L., Stahl D. A. and Ingalls A. E. (2010) Changes in intact membrane lipid content of archaeal cells as an indication of metabolic status. Org. Geochem. 41, 930-934.

Ingalls A. E., Shah S. R., Hansman R. L., Aluwihare L. I., Santos G. M., Druffel E. R. M. and Pearson A. (2006) Quantifying archaeal community autotrophy in the mesopelagic ocean using natural radiocarbon. Proc. Natl. Acad. Sci. USA 103, 64426447.

Jensen M. M., Lam P., Revsbech N. P., Nagel B., Gaye B., Jetten M. S. M. and Kuypers M. M. M. (2011) Intensive nitrogen loss over the Omani Shelf due to anammox coupled with dissimilatory nitrite reduction to ammonium. Int. Soc. Microb. Ecol. 5, 1660-1670.

Karner M. B., DeLong E. F. and Karl D. M. (2001) Archaeal dominance in the mesopelagic zone of the Pacific Ocean. Nature 409, 507-510.

Kates M., Yengoyan L. S. and Sastry G. N. (1965) A diether analog of phosphatidyl glycerophosphate in Halobacterium cutirubrum. Biochim. Biophys. Acta 98, 252-268.

Kim J.-H., Schouten S., Hopmans E. C., Donner B. and Sinninghe Damsté J. S. (2008) Global sediment core-top calibration of the $\mathrm{TEX}_{86}$ paleothermometer in the ocean. Geochim. Cosmochim. Acta 72, 1154-1173.

Kim J.-H., van der Meer J., Schouten S., Helmke P., Willmott V., Sangiorgi F., Koç N., Hopmans E. C. and Sinninghe Damsté J. S. (2010) New indices and calibrations derived from the distribution of crenarchaeal isoprenoid tetraether lipids: implications for past sea surface temperature reconstructions. Geochim. Cosmochim. Acta. 74, 4639-4654.

Koga Y. and Morii H. (2005) Recent advances in structural research on ether lipids from archaea including comparative and physiological aspects. Biosci. Biotechnol. Biochem. 69, 2019-2034.

Koga Y. and Nakano M. (2008) A dendrogram of archaea based on lipid component parts composition and its relationship to rRNA phylogeny. Syst. Appl. Microbiol. 31, 169-182.

Könneke M., Bernhard A. E., de la Torre J. R., Walker C. B., Waterbury J. B. and Stahl D. A. (2005) Isolation of an autotrophic ammonia-oxidizing marine archaeon. Nature 437, 543-546.

Kraal P., Slomp C. P., Reed D. C., Reichart G. J. and Poulton S. W. (2012) Sedimentary phosphorus and iron cycling in and below the oxygen minimum zone of the Northern Arabian Sea. Biogeosci. Discuss. 9, 3829-3880.

Kuypers M. M. M., Blokker P., Erbacher J., Kinkel H., Pancost R. D., Schouten S. and Sinninghe Damsté J. S. (2001) Massive expansion of marine archaea during a mid-cretaceous oceanic anoxic event. Science 293, 92-94.

Langworthy T. A., Smith P. F. and Mayberry W. R. (1972) Lipids of Thermoplasma acidophilum. J. Bacteriol. 112, 1193-1200.

Langworthy T. A., Mayberry W. R. and Smith P. F. (1974) Longchain glycerol diether and polyol dialkyl glycerol triether lipids of Sulfolobus acidocaldarius. J. Bacteriol. 119, 106-116.

Lebaron P., Servais P., Agogué H., Courties C. and Joux F. (2001) Does the high nucleic acid content of individual bacterial cells allow us to discriminate between active cells and inactive cells in aquatic systems? Appl. Environ. Microbiol. 67, 1775-1782.

Leininger S., Urich T., Schloter M., Schwark L., Qi J., Nicol G. W., Prosser J. I., Schuster S. C. and Schleper C. (2006) Archaea predominate among ammonia-oxidizing prokaryotes in soils. Nature 442, 806-809.
Lengger S. K., Hopmans E. C., Sinninghe Damsté J. S. and Schouten S. (2012) A comparison of extraction and work-up techniques for analysis of core- and intact polar tetraether lipids in marine sediments. Org. Geochem. 47, 34-40.

Lipp J. S. and Hinrichs K.-U. (2009) Structural diversity and fate of intact polar lipids in marine sediments. Geochim. Cosmochim. Acta 73, 6816-6833.

Lipp J. S., Morono Y., Inagaki F. and Hinrichs K.-U. (2008) Significant contribution of Archaea to extant biomass in marine subsurface sediments. Nature 454, 991-994.

Liu Z., Pagani M., Zinniker D., DeConto R., Huber M., Brinkhuis H., Shah S. R., Leckie R. M. and Pearson A. (2009) Global cooling during the Eocene-Oligocene climate transition. Science 323, 1187-1189.

Liu X., Lipp J. S. and Hinrichs K.-U. (2011) Distribution of intact and core GDGTs in marine sediments. Org. Geochem. 42, 368375.

Lopes dos Santos R. A., Prange M., Castañeda I. S., Schefuß E., Mulitza S., Schulz M., Niedermeyer E. M., Sinninghe Damsté J. S. and Schouten S. (2010) Glacial-interglacial variability in Atlantic meridional overturning circulation and thermocline adjustments in the tropical North Atlantic. Earth Planet. Sci. Lett. 300, 407-414.

Luna G. M., Manini E. and Danovaro R. (2002) Large fraction of dead and inactive bacteria in coastal marine sediments: comparison of protocols for determination and ecological significance. Appl. Environ. Microbiol. 68, 3509-3513.

Macalady J. L., Vestling M. M., Baumler D., Boekelheide N., Kaspar C. W. and Banfield J. F. (2004) Tetraether-linked membrane monolayers in Ferroplasma spp a key to survival in acid. Extremophiles 8, 411-419.

Mayer L. M. (1994) Surface area control of organic carbon accumulation in continental shelf sediments. Geochim. Cosmochim. Acta 58, 1271-1284.

Mayer L. M., Schick L. L., Hardy K. R., Wagai R. and McCarthy J. (2004) Organic matter in small mesopores in sediments and soils. Geochim. Cosmochim. Acta 68, 3863-3872.

Oba M., Sakata S. and Tsunogai U. (2006) Polar and neutral isopranyl glycerol ether lipids as biomarkers of archaea in nearsurface sediments from the Nankai. Org. Geochem. 37, 16431654.

Olson D. B., Hitchcock G. L., Fine R. A. and Warren B. A. (1993) Maintenance of the low-oxygen layer in the central Arabian Sea. Deep Sea Res. Part II 40, 673-685.

Pancost R. D., Hopmans E. C., Sinninghe Damsté J. S. and the Medinaut Shipboard Scientific Party (2001) Archaeal lipids in Mediterranean Cold Seeps: molecular proxies for anaerobic methane oxidation. Geochim. Cosmochim. Acta 65, 1611-1627.

Park S.-J., Park B.-J. and Rhee S.-K. (2008) Comparative analysis of archaeal 16S rRNA and amo $A$ genes to estimate the abundance and diversity of ammonia-oxidizing archaea in marine sediments. Extremophiles 12, 605-615.

Park B.-J., Park S.-J., Yoon D.-N., Schouten S., Sinninghe Damsté J. S. and Rhee S.-K. (2010) Cultivation of autotrophic ammonia-oxidizing archaea from marine sediments in coculture with sulfur-oxidizing bacteria. Appl. Environ. Microbiol. 76, 7575-7587.

Paulmier A. and Ruiz-Pino D. (2009) Oxygen minimum zones (OMZs) in the modern ocean. Prog. Oceanogr. 80, 113-128.

Pearson A., McNichol A. P., Benitez-Nelson B. C., Hayes J. M. and Eglinton T. I. (2001) Origins of lipid biomarkers in Santa Monica Basin surface sediment: a case study using compoundspecific $\mathrm{D}^{14} \mathrm{C}$ analysis. Geochim. Cosmochim. Acta 65, 31233137.

Pitcher A., Hopmans E. C., Schouten S. and Sinninghe Damsté J. S. (2009) Separation of core and intact polar archaeal tetraether 
lipids using silica columns: insights into living and fossil biomass contributions. Org. Geochem. 40, 12-19.

Pitcher A., Rychlik N., Hopmans E. C., Spieck E., Rijpstra W. I. C., Ossebaar J., Schouten S., Wagner M. and Sinninghe Damsté J. S. (2010) Crenarchaeol dominates the membrane lipids of Candidatus Nitrososphaera gargensis, a thermophilic Group I.1b Archaeon. Int. Soc. Microb. Ecol. 4, 542-552.

Pitcher A., Hopmans E. C., Villanueva L., Reichart G.-J., Schouten S. and Sinninghe Damsté J. S. (2011) Niche segregation of ammonia-oxidizing archaea and anammox bacteria in the Arabian Sea oxygen minimum zone. ISME J. 5, 1896-1904.

Pitcher A., Hopmans E. C., Mosier A. C., Park S.-J., Rhee S.-K., Francis C. A., Schouten S. and Sinninghe Damsté J. S. (2011) Core and intact polar glycerol dibiphytanyl glycerol tetraether lipids of ammonia-oxidizing archaea enriched from marine and estuarine sediments. Appl. Environ. Microbiol. 77, 3468-3477.

Prahl F. G., de Lange G. J., Scholten S. and Cowie G. L. (1997) A case of post-depositional aerobic degradation of terrestrial organic matter in turbidite deposits from the Madeira Abyssal Plain. Org. Geochem. 27, 141-152.

Revsbech N. P. (1989) An oxygen microsensor with a guard cathode. Limnol. Oceanogr. 34, 474-478.

Revsbech N. P., Larsen L. H., Gundersen J., Dalsgaard T., Ulloa O. and Thamdrup B. (2009) Determination of ultra-low oxygen concentrations in oxygen minimum zones by the STOX sensor. Limnol. Oceanogr. Methods 7, 371-381.

Schleper C., Holben W. and Klenk H.-P. (1997) Recovery of crenarchaeotal ribosomal DNA sequences from freshwater-lake sediments. Appl. Environ. Microbiol. 63, 321-323.

Schouten S., Hopmans E. C., Pancost R. D. and Sinninghe Damsté J. S. (2000) Widespread occurrence of structurally diverse tetraether membrane lipids: evidence for the ubiquitous presence of low-temperature relatives of hyperthermophiles. Proc. Natl. Acad. Sci. USA 97, 14421-14426.

Schouten S., Hopmans E. C., Schefuß E. and Sinninghe Damsté J. S. (2002) Distributional variations in marine crenarchaeotal membrane lipids: a new tool for reconstructing ancient sea water temperatures? Earth Planet. Sci. Lett. 204, 265-274.

Schouten S., Forster A., Panoto F. E. and Sinninghe Damsté J. S. (2007) Towards calibration of the $\mathrm{TEX}_{86}$ palaeothermometer for tropical sea surface temperatures in ancient greenhouse worlds. Org. Geochem. 38, 1537-1546.

Schouten S., Hopmans E. C., Baas M., Boumann H., Standfest S., Könneke M., Stahl D. A. and Sinninghe Damsté J. S. (2008) Intact membrane lipids of "Candidatus Nitrosopumilus maritimus", a cultivated representative of the cosmopolitan mesophilic group I crenarchaeota. Appl. Environ. Microbiol. 74, 2433-2440.

Schouten S., Middelburg J. J., Hopmans E. C. and Sinninghe Damsté J. S. (2010) Fossilization and degradation of intact polar lipids in deep subsurface sediments: a theoretical approach. Geochim. Cosmochim. Acta 74, 3806-3814.

Schouten S., Pitcher A., Hopmans E. C., Villanueva L., van Bleijswijk J. and Sinninghe Damsté J. S. (2012) Intact polar and core glycerol dibiphytanyl glycerol tetraether lipids in the Arabian Sea oxygen minimum zone: I. Selective preservation and degradation in the water column and its consequences for the $\mathrm{TEX}_{86}$. Geochim. Cosmochim. Acta 98, 228-243.

Schubotz F., Wakeham S. G., Lipp J. S., Fredricks H. F. and Hinrichs K.-U. (2009) Detection of microbial biomass by intact polar membrane lipid analysis in the water column and surface sediments of the Black Sea. Environ. Microbiol. 11, 2720-2734.
Shah S. R., Mollenhauer G., Ohkouchi N., Eglinton T. and Pearson A. (2008) Origins of archaeal tetraether lipids in sediments: insights from radiocarbon analysis. Geochim. Cosmochim. Acta 72, 4577-4594.

Sinninghe Damsté J. S., Rijpstra W. I. C. and Reichart G.-J. (2002a) The influence of oxic degradation on the sedimentary biomarker record II. Evidence from Arabian Sea sediments. Geochim. Cosmochim. Acta 66, 2737-2754.

Sinninghe Damsté J. S., Schouten S., Hopmans E. C., van Duin A. C. T. and Geenevasen J. A. J. (2002b) Crenarchaeol: the characteristic core glycerol dibiphytanyl glycerol tetraether membrane lipid of cosmopolitan pelagic crenarchaeota. $J$. Lipid Res. 43, 1641-1651.

Spang A., Hatzenpichler R., Brochier-Armanet C., Rattei T., Tischler P., Spieck E., Streit W., Stahl D. A., Wagner M. and Schleper C. (2010) Distinct gene set in two different lineages of ammonia-oxidizing archaea supports the phylum Thaumarchaeota. Trends Microbiol. 18, 331-340.

Stevenson P. L. (1978) A case for bacterial dormancy in aquatic systems. Microb. Ecol. 4, 127-133.

Sturt H. F., Summons R. E., Smith K., Elvert M. and Hinrichs K.U. (2004) Intact polar membrane lipids in prokaryotes and sediments deciphered by high-performance liquid chromatography/electrospray ionization multistage mass spectrometry new biomarkers for biogeochemistry and microbial ecology. Rapid Commun. Mass Spectrom. 18, 617-628.

van der Weijden C. H., Reichart G.-J. and Visser H. J. (1999) Enhanced preservation of organic matter in sediments deposited within the oxygen minimum zone in the northeastern Arabian Sea. Deep Sea Res. Part I 46, 807-830.

Wakeham S. G., Lewis C. M., Hopmans E. C., Schouten S. and Sinninghe Damsté J. S. (2003) Archaea mediate anaerobic oxidation of methane in deep euxinic waters of the Black Sea. Geochim. Cosmochim. Acta 67, 1359-1374.

Weijers J. W. H., Lim K. L., Aquilina A., Sinninghe Damsté J. S. and Pancost R. D. (2011) Biogeochemical controls on glycerol dialkyl glycerol tetraether lipid distributions in sediments characterized by diffusive methane flux. Geochem. Geophys. Geosyst. 12, Q10010.

Wuchter C., Schouten S., Coolen M. J. L. and Sinninghe Damsté J. S. (2004) Temperature-dependent variation in the distribution of tetraether membrane lipids of marine Crenarchaeota: implications for TEX86 paleothermometry. Paleoceanography 19, PA4028.

Wuchter C., Schouten S., Wakeham S. G. and Sinninghe Damsté J. S. (2005) Temporal and spatial variation in tetraether membrane lipids of marine Crenarchaeota in particulate organic matter: implications for TEX86 paleothermometry. Paleoceanography 20, PA3013-1-PA3013-11.

Wuchter C., Schouten S., Wakeham S. G. and Sinninghe Damsté J. S. (2006) Archaeal tetraether membrane lipid fluxes in the northeastern Pacific and the Arabian Sea: implications for TEX86 paleothermometry. Paleoceanography 21, PA4208.

Wyrtki K. (1971) Oceanographic Atlas of the International Indian Ocean Expedition. USGPO, Washington.

Wyrtki K. (1973) Physical geography of the Indian Ocean. In The Biology of the Indian Ocean. Springer, Berlin, pp. 18-36.

Zink K.-G., Wilkes H., Disko U., Elvert M. and Horsfield B. (2003) Intact phospholipids - microbial "life markers" in marine deep subsurface sediments. Org. Geochem. 34, 755-769.

Associate editor: Josef P. Werne 